\title{
The Distribution of Proenkephalin-Derived Peptides in the Central Nervous System of Turtles
}

\author{
ANTON REINER \\ Department of Anatomy and Cell Biology, The University of Michigan, \\ Ann Arbor, Michigan 48109
}

\begin{abstract}
The present study was carried out to examine if peptides similar to the various opioid peptide products of mammalian proenkephalin are present in the turtle central nervous system and to determine their distribution. Antisera against several enkephalin peptides were used: 1) leucine-enkephalin (LENK), 2) methionine-enkephalin (MENK), 3) methionine-enkephalin-arg ${ }^{6}$ phe $^{7}$ (MERF), 4) methionine-enkephalin-arg ${ }^{6}$-gly ${ }^{7}-$ leu $^{8}$ (MERGL), 5) Peptide E (PEPE), and 6) BAM22P. Their specificity and cross-reactivity were carefully examined. The results indicated that LENK, MENK, and MERF (or highly similar peptides) are present in the turtle central nervous system, and that a peptide showing immunological similarity to BAM22P and PEPE also appeared to be present. In contrast, MERGL did not appear to be present. The distributions of the immunoreactive labeling for LENK, MENK, MERF, BAM22P, and PEPE were indistinguishable, and double-label studies showed that LENK, MERF, and BAM22P were colocalized within individual neurons and fibers. Although all of the above substances were observed in the same cell groups, there was some regional variation, in terms of which enkephalin peptide appeared to be most abundant.

The distributions of these enkephalin peptides were very similar to those previously described in mammals and birds. Enkephalin was more abundant in the basal ganglia than in overlying telencephalic regions. Within the basal ganglia, enkephalin was present in striatal neurons and fibers and in pallidal fibers, thereby suggesting the existence of an enkephalinergic striatopallidal projection. Sensory relay nuclei of the thalamus were generally poor in enkephalinergic fibers, whereas the hypothalamus was rich in enkephalinergic neurons and fibers. Enkephalinergic neurons and fibers were present in the midbrain central gray. As is true of neurons of the nucleus spiriformis lateralis of the avian pretectum, the neurons of the homologous cell group in turtles, the dorsal nucleus of the posterior commissure of the pretectum, were found to contain enkephalin and have an enkephalinergic projection to the deep layers of the ipsilateral tectum. Enkephalinergic neurons and fibers were also abundant in the entry zones of the trigeminal nerve and dorsal root fibers of the spinal cord.

The present results indicate that: 1) consistent with previously published biochemical studies (Lindberg and White, '86), proenkephalin in reptiles is similar in structure to that of mammals and, with the exception of MERGL, gives rise to similar or identical enkephalin peptides, and 2) the enkephalin peptides are found in many of the same systems of reptilian brain as mammalian and avian brain, and, therefore, may play a role in similar functions (e.g., basal ganglia motor functions) as in mammals and birds.
\end{abstract}


Key words: immunohistochemistry, basal ganglia, enkephalin peptides, opioid peptides, reptiles, evolution

Three distinct families of opioid peptides-the enkephalin peptides, the dynorphin peptides, and the endorphin peptides-have been identified in the nervous system in mammals (Hughes et al., '75; Akil et al., '84; Weber et al., '83; Khachaturian et al., ' 85 ). The peptides within each opioid peptide family are related in that they all derive from a common large precursor molecule-proenkephalin in the case of enkephalin peptides, prodynorphin in the case of the dynorphin peptides, and POMC in the case of the endorphin peptides (Lewis et al., '79; Stern et al., '79; Mizuno et al., '80; Rossier et al., '80; Kilpatrick et al., '81; Comb et al., '82; Jones et al., '82a,b; Kakidani et al., '82; Noda et al., '82; Bloch et al., '83; Gubler et al., '84). Since the members of a given opioid family have a common precursor, those members necessarily co-occur within individual neurons of the nervous system (Rossier et al., '80; Bloch et al., '83; Khachaturian et al., '83b, '85; Watson et al., '83; Weber et al., '83; Akil et al., '84). Although the CNS distribution of the three families of opioid peptides shows some overlap, the families: 1) are almost exclusively found in different neurons, 2) have different distributions, and 3) presumably play different (although possibly somewhat overlapping) roles in CNS function (Bloom et al., '78; Watson et al., '78, '82b; Weber et al., '83; Akil et al., '84; Khachaturian et al., '85).

Opioid peptides have also been found in nervous tissue in members of a wide variety of nonmammalian animal taxa, ranging from planarians to birds (Simantov et al., '76; Dubois et al., '79; Bayon et al., '80; Blahser and Dubois, '80; Jackson et al., '80; Reaves and Hayward, '80; Zipser, '80; De Lanerolle et al., '81; Doerr-Schott et al., '81; Finger, '81; Ryan et al., '81; Schulman et al., '81; Brauth and Reiner, '82; Dores, '82a; Gold and Finger, '82; Kuljis and Karten, '82; Reiner et al., '82b, '84b; LaValley and Ho, '83; Northcutt et al., '83, '86; Reiner, '83, '87; Brauth, '84; Georges and Durois, ' 84 ; Khachaturian et al., ' 84 ; Nozaki and Gorbman, '84, '85; Rzasa et al., '84; Reiner and Northcutt, '87). Several biochemical studies using RIA and/or HPLC have shown that members of each of the three families of opioid peptides are present in the nervous sytems of modern amphibians, thereby suggesting that the three distinct opioid peptide families had evolved as of early amphibians (Loh, '79; Cone and Goldstein, '82; King and Millar, '80; Kilpatrick et al., '83; Martens and Herbert, '84). The pentapeptide members of the enkephalin family have, in fact, been found in earthworm nervous tissue (Rzasa et al., ' 84 ), suggesting that the enkephalin peptides might have appeared in the nervous system prior to the vertebrate-invertebrate divergence.

Since the three distinct opioid peptide families appear to have evolved as of the early amphibians (if not earlier), it is not surprising that the available data strongly support the conclusion that endorphin peptides, enkephalin peptides, and dynorphin peptides are all present in the CNS of reptiles. The presence of endorphin peptides has been demonstrated in the reptilian nervous system and pituitary in a series of biochemical and immunohistochemical studies on Anolis by Dores and coworkers (Dores, '82a,b, '83; Dores and Surprenant, '83, '84; Dores et al., '84; Khachaturian et al., 84). The presence of several enkephalin peptides in the reptilian nervous system has been suggested by immuno- histochemical studies (Naik et al., '81; Brauth and Reiner, '82; Brauth, '84; Wolters et al., '86) and confirmed by a recent biochemical study (Lindberg and White, '86). The presence of dynorphin peptides in the nervous system of reptiles has been demonstrated immunohistochemically with antisera that do not cross-react with enkephalin peptides (Reiner, '83, '86). In previous immunohistochemical studies, however, the distribution of enkephalin peptides in the reptilian nervous system has been examined using only antisera against leucine-enkephalin (LENK) and methionine-enkephalin (MENK) (Naik et al., '81; Brauth and Reiner, '82; Brauth, '84; Wolters et al., '86). In light of the potential cross-reactivity of anti-LENK or anti-MENK antisera with dynorphin peptides (which all contain the LENK sequence at their $\mathrm{N}$-terminus), it is possible that previous studies on the distributions of LENK + (or MENK +) cell bodies and fibers have not distinguished between enkephalinergic and dynorphinergic neurons (McGinty et al., '83; Reiner, '83; Reiner et al., '84b). In the present study, the distributions of several members of the enkephalin family of peptides were examined using immunohistochemistry. These enkephalin peptides included LENK, MENK, methionine-enkephalin-Arg ${ }^{6}-\mathrm{Phe}^{7}$ (MERF), methionine-enkephalin-Arg ${ }^{6}-$ Gly $^{7}-$ Leu $^{8}$ (MERGL), BAM22P, and Peptide E (PEPE). In the case of LENK, MENK, and MERF, several different antisera against each were used. Since the antisera against the larger enkephalin peptides were found not to cross-react with dynorphin, their use allowed the unequivocal determination of the distribution of enkephalinergic perikarya and fibers in the reptilian CNS. Further, it was thought that the present studies, in conjunction with previous biochemical studies, might shed further light on the identities of the various enkephalin peptides present in the turtle nervous system and, therefore, on the similarity of turtle proenkephalin to mammalian proenkephalin.

\section{MATERIALS AND METHODS}

Both red-eared (Pseudemys scripta) and painted turtles (Chryemys picta) were used in the present study. Turtles were housed as described previously; some turtles received an intraventricular injection of colchicine $(60 \mu \mathrm{g} / 3 \mu \mathrm{l}$ distilled $\mathrm{H}_{2} \mathrm{O}$ ) to enhance perikaryal immunoreactivity, as described previously (Reiner and Beinfeld, '85). Turtles were deeply anesthetized with ketamine and perfused transcardially with $6 \%$ dextran in phosphate buffer $(\mathrm{pH} 7.2)$, followed by $4 \%$ paraformaldehyde in phosphate buffer ( $\mathrm{pH}$ 7.2). Colchicine-treated turtles were perfused 72-120 hours after the colchicine injection. After perfusion, the brains were removed and postfixed in $4 \%$ paraformaldehyde in phosphate buffer ( $\mathrm{pH}$ 10.4) for 2-16 hours. The brains were then immersed in sucrose-phosphate buffer for 24-48 hours and sectioned frozen at 40 microns on a sliding microtome. Sections were processed for immunohistochemistry according to either the immunofluorescence technique (Coons, '58) or the PAP technique (Sternberger, '79). The details of our use of these procedures has been described previously (Reiner et al., ' $84 b, c$; Reiner and Beinfeld, ' 85 ). In brief, tissue was washed 3 times in $0.1 \mathrm{M}$ phosphate buffer ( $\mathrm{pH} 7.2)(\mathrm{PB})$ and incubated at $4^{\circ} \mathrm{C}$ in the primary antiserum for $48-72$ hours. For the immunofluorescence procedure, after wash- 
ing 3 times in $\mathrm{PB}$, tissue was incubated for 1 hour at room temperature in FITC-labeled secondary antiserum directed against the IgG of the animal species in whom the primary antiserum was raised. After washing 3 times in $P B$, tissue was then mounted and examined by means of a Leitz epiillumination fluorescence microscopy system. For the PAP technique, after incubation in the primary antiserum and 3 washes in PB, tissue was incubated for 1 hour at room temperature in an unlabeled secondary antiserum directed against the IgG of the animal species in whom the primary antiserum was raised. Tissue was then washed 3 times in $\mathrm{PB}$ and incubated for 1 hour at room temperature in peroxidase-antiperoxidase (with antiperoxidase raised in the same animal species as the primary antiserum). After 3 washes in $\mathrm{PB}$, the tissue was processed for HRP visualization with diaminobenzidine tetrahydrochloride (DAB). Tissue was preincubated in a solution of DAB (100 mg DAB. $4 \mathrm{HCl}$ in $100 \mathrm{ml} .05 \mathrm{M}$ cacodylate-.05 M imidazole buffer, $\mathrm{pH}$ 7.0) for 10 minutes, followed by an additional 10 minutes' incubation in this solution following addition of $300 \mu \mathrm{l}$ of $3 \% \mathrm{H}_{2} \mathrm{O}_{2}$ per $100 \mathrm{ml}$ incubating medium. Tissue was then washed, mounted on gelatin-coated slides, and coverslipped. Cell groups of the turtle brain and terminology for these cell groups were as used previously (Powers and Reiner, '80; Reiner et al., '84c; Reiner and Beinfeld, '85).

Antisera against several different enkephalin peptides were used in the present study (see Table 1): anti-LENK (A206, courtesy of K.J. Chang), anti-LENK (ImmunoNuclear Corp.), anti-LENK (mouse monoclonal antibody obtained from Sera-Labs, Accurate Chemical Co.), antiMENK (A900, courtesy of K.J. Chang), anti-MENK (ImmunoNuclear Corp.), anti-BAM22P (RB334B6, courtesy of A. Baird), anti-MERF (L150, courtesy of G.J. Dockray), anti-MERF (courtesy of H.Y.T. Yang), anti-MERGL (L189, courtesy of G.J. Dockray), and anti-PEPE (courtesy of S.J Watson). The specificities and cross-reactivities of the above antisera have been described in previous studies (Miller et al., '78; Williams and Dockray, '82, '83; Bloch et al., '83; Majane et al., '83; Cuello et al., '84; Giraud et al., '84; Reiner et al., '84b) and were examined in detail during the present study. The present findings on the specificity of the above antisera are described in the Results section. In brief, the antisera against BAM22P, PEPE, MERGL, and MERF showed little or no cross-reactivity with dynorphin peptides. Both the MENK antisera and the ImmunoNuclear antiLENK antiserum showed negligible cross-reactivity with longer dynorphin peptides, but they did show some crossreactivity with a shorter dynorphin peptide, Dynorphin A(1-8). The Chang A206 anti-LENK antiserum has been previously reported to show considerable cross-reactivity with Dynorphin A(1-8) (Reiner et al., '84b; McGinty et al., '83). The monoclonal anti-LENK antibody reportedly shows no cross-reactivity with Dynorphin A(1-13) (Cuello et al., '84). The above antisera were generally found to show little cross-reactivity with enkephalin peptides other than their target peptide, except that the LENK and MENK antisera recognized each other's antigens to a significant extent and the BAM22P and PEPE antisera recognized each other's antigens. To further distinguish enkephalin-containing cell and fibers from dynorphin-containing cells and fibers, the distribution of the labeling obtained with the various en kephalin antisera was compared to that obtained with an antiserum highly specific for the C-terminus of Dynorphin $A(1-17)$ (obtained from $L$. Terenius). It was found that none of the above enkephalin antisera, except the A206, produced even light labeling of the dynorphinergic striatonigral tract of turtles (Reiner, '86a) and the A206 produced only light labeling of the striatonigral tract.

To determine whether LENK is present in the same enkephalinergic neurons as the other enkephalin peptides, a simultaneous immunofluorescence procedure was used, as described previously (Erichsen et al., '82; Reiner et al., '85; Wessendorf and Elde, '85), to colocalize LENK (with the monoclonal antibody) with each of the following: BAM22P (with the anti-BAM22P antiserum) and MERF (with Dockray's anti-MERF antiserum). As noted below, the monoclonal antibody shows no cross-reactivity with either BAM22P or MERF. Further, neither the anti-BAM22P antiserum nor the anti-MERF antiserum cross-reacts with LENK. Tissue was incubated in a primary antiserum mixture containing 1:10 monocional anti-LENK and one of the two other primary antisera noted above (both raised in $\mathrm{Rb}$ ) at a 1:500 dilution for 48-72 hours. Tissue was washed 3 times in PB and incubated in a secondary antisera mixture containing 1:50 goat antimouse IgG conjugated to FITC and 1:50 goat antirabbit IgG conjugated to TRITC for 1 hour at room temperature. Tissue was washed, mounted on gelatin-coated slides, and coverslipped with 9:1 glycerol-carbonate buffer (pH 9.0) and examined with a Leitz epi-illumination fluorescence microscopy system. Double-labeled cells and fibers were identified by successively viewing FITC-labeling (with the I2 cube) and TRITC-labeling (with the N2 cube) of individual neurons and fibers.

\section{RESULTS Antibody specificity}

The results of the blocking and cross-blocking studies performed are presented in Table 1. All of the antisera examined could be blocked with 25-100 microMolar amounts of their target peptide. Cross-blocking data are based on the use of 50-100 microMolar concentrations of the peptide used for cross-blocking studies. Data for the Chang A206 anti-LENK are based on previous studies (Miller et al., '78; McGinty et al., '83; Cuello et al., '84; Reiner et al., ' $84 b$ ). As can be seen, the Chang anti-LENK antiserum shows significant cross-reactivity with MENK and Dynorphin A(1-8). Thus, the Chang A206 antiserum appears to be largely directed at the N-terminus of LENK, which would account for the extensive cross-reactivity of the antiserum with peptides that possess the same N-terminal amino acid sequence as LENK. In comparison, the ImmunoNuclear anti-LENK antiserum shows much less cross-reactivity with Dynorphin A(1-8), and negligible crossreactivity with Dynorphin A(1-17) and Dynorphin A(1-13). Among the enkephalin peptides, the ImmunoNuclear antiLENK antiserum cross-reacts considerably with MENK and PEPE, but only slightly with MERF, BAM12P, and BAM22P. These results suggest that the ImmunoNuclear anti-LENK antiserum is largely specific for the C-terminus of LENK, with some cross-reactivity for small peptides (i.e., MENK and Dynorphin A 1-8) possessing the same N-terminus as LENK. The greater cross-reactivity of the ImmunoNuclear anti-LENK antiserum with PEPE than with BAM22P presumably reflects the fact that both the $\mathrm{N}$ terminus and the C-terminus of PEPE are identical to those of LENK, whereas only the N-terminus of BAM22P is identical to that of LENK. The monoclonal anti-LENK antibody is reported to show considerable cross-reactivity with MENK, and no cross-reactivity with Dynorphin A(1-13), or 


\section{Abbreviations}

a area a (Riss et al., '69)

AP area pretectalis

AT area triangularis

BA nucleus basalis amygdalae

BOR basal optic root

CA nucleus centralis amygdalae

$\mathrm{Cb}$ cerebellum

$\mathrm{CbL}$ nucleus cerebellaris lateralis

$\mathrm{CbM}$ nucleus cerebellaris medialis

cd cortex dorsalis

cdm cortex dorsomedialis

$\mathrm{cm}$ cortex medialis

CN core nucleus of the DVR

CO chiasma opticum

Co cochlear nuclei

CP commissura posterior

cp cortex pyriformis

$\mathrm{cpv} \quad$ cortex pyriformis, pars ventralis

d area d (Riss et al., '69)

d IV decussatio nervi trochlearis

DLA nucleus dorsolateralis anterior

DMA nucleus dorsomedialis anterior

DSOD dorsal nucleus of the supraoptic decussation

DVR dorsal ventricular ridge of the telencephalon

FD funiculus dorsalis

FL, funiculus lateralis

FLM fasciculus longitudinalis medialis

FRL formatio reticularis lateralis mesencephali

FV funiculus ventralis

GC griseum centrale

GCL granule cell layer

GLd nucleus geniculatus lateralis pars dorsalis

GLv nucleus geniculatus lateralis pars ventralis

GP globus pallidus

HL nucleus habenularis lateralis

HM nucleus habenularis medialis

IP nucleus interpeduncularis

Imc nucleus isthmi magnocellularis, pars caudalis

Imr nucleus isthmi magnocellularis, pars rostralis

Ipc nucleus isthmi parvocellularis

LA nucleus laminaris of the torus semicircularis

LGE laminaris granularis externa

LGI laminaris granularis interna

LL lateral lemniscus

LM nucleus lentiformis mesencephali

LoC locus coeruleus

$\mathrm{M}$ nucleus mamillaris

MA nucleus medialis amygdalae

MC mitral cell layer

ME median eminence

ML molecular layer

M V nucleus mesencephalicus nervi trigemini

$\mathrm{m}$ V nucleus motorius nervi trigemini

NHy neurohypophysis

NPd nucleus pretectalis dorsalis

NPv nucleus pretectalis ventralis

$\mathrm{NV}$ nervus trigemini

N VIII nervus octavus

nAmb nucleus ambiguus

$n B O R$ nucleus of the basal optic root

$\mathrm{nDB}$ nucleus fasciculus diagonalis Brocae

nDCP nucleus dorsalis commissuralae posterioris

nFLM nucleus fasciculi longitudinalis medialis

$\mathrm{nMH}$ nucleus medialis hypothalami

$\mathrm{nPH}$ nucleus periventricularis hypothalami

nPM nucleus profundus mesencephali

nS nucleus septalis

nSL nucleus septalis lateralis

nSM nucleus septalis medialis

nSO nucleus supraopticus

$\mathrm{nSP}$ nucleus suprapeduncularis

nSPM nucleus suprapeduncularis medialis

nTOL nucleus tracti olfactorii lateralis

nTS nucleus tracti solitarii

$\mathrm{nV}$ nucleus ventralis

nVH nucleus ventromedialis hypothalami

$n$ III nucleus nervi oculomotorius

$n$ IV nucleus nervi trochlearis

$n$ VI nucleus nervi abducens

$n$ VII nucleus nervi facialis
$\mathrm{nX}$ nucleus motorius dorsalis nervi vagi

$\mathrm{nXII}$ nucleus nervi hypoglossi

OI oliva inferior

OS oliva superior

PA paleostriatum augmentatum

$\mathrm{Pb}$ nucleus parabrachialis

PD peduncularis dorsalis fasciculi prosencephali lateralis

$\mathrm{PH}$ primordium hippocampi

$\operatorname{Pr} \mathrm{V}$ nucleus princeps nervi trigemini

PT pallial thickening

PV peduncularis ventralis fasciculi prosencephali lateralis

R nucleus rotundus

Rai nucleus raphes inferior

Ras nucleus raphes superior

$\mathrm{Re} \quad$ nucleus reuniens

$\mathrm{Ri}$ nucleus reticularis inferior

Ris nucleus reticularis isthmi

$\mathrm{Rm}$ nucleus reticularis medialis

Rs nucleus reticularis superior

$\mathrm{Ru}$ nucleus ruber

SGC stratum griseum centrale

SGD nucleus substantiae griseae dorsalis

SGF stratum griseum et fibrosum superficiale

SGP stratum griseum periventriculare

SGV substantiae griseae ventralis

SM stria medullaris

$\mathrm{Sm} \quad$ supramamillary region

SN substantia nigra

SO stratum opticum

ST stria terminglis

$\mathrm{Ta}$ nucleus tangentialis

Tel telencephalon

$\mathrm{TeO}$ tectum opticum

TO tractus opticus

TO1 tractus opticus, pars lateralis

TOm tractus opticus, pars medialis

TrL tract of Lissauer

TSC torus semicircularis

TTd nucleus descendens nervi trigemini

TuOl tuberculum olfactorium

TT tractus tectothalamicus

V ventricle

$\mathrm{VeD}$ nucleus vestibularis descendens

VeL nucleus vestibularis lateralis

VeS nucleus vestibularis superior

VP ventral paleostriatum

with MERF (Cuello et al., '84). In the present study, this antiserum was additionally found to show no cross-reactivity with BAM22P, and the absence of cross-reactivity with MERF was confirmed. Thus, the monoclonal anti-LENK antibody appears to be specific for the enkephalin pentapeptides. The Chang anti-MENK antiserum showed considerable cross-reactivity with LENK (Miller et al., '78; Gall et al., '81; Reiner et al., '82b). The cross-reactivity of this antiserum with dynorphin peptides or the larger enkephalin peptides was not examined. The ImmunoNuclear antiMENK antiserum showed no or negligible cross-reactivity with the dynorphin peptides, but some slight cross-reactivity with LENK, MERF, BAM22P, and PEPE. Thus, the ImmunoNuclear anti-MENK antiserum appears to be largely specific for MENK. Both of the anti-MERF antisera were highly specific for MERF, with negligible or no crossreactivity with the dynorphin peptides or with the various other enkephalin peptides. Dockray's anti-MERF antiserum appeared to be more specific for MERF-OH, since it was blocked by MERF-OH but not by MERF-NH $\mathrm{N}_{2}$, as previously reported (Williams and Dockray, '83). Yang's antiMERF antiserum appeared to be more specific for MERF. $\mathrm{NH}_{2}$ since it was blocked by MERF- $\mathrm{NH}_{2}$, but only partially blocked by MERF-OH. Thus, although Yang's antiserum may have some cross-reactivity with FMRFamide (Dockray et al., '81), which possesses the same C-terminus tetrapep- 
tide sequence as MERF-NH, it produced the same labeling pattern in the turtle brain as Dockray's anti-MERF antiserum. So, it appears unlikely that labeling observed with Yang's antiserum was due, to any great extent, to crossreactive labeling of FMRFamide-containing neurons and fibers. The anti-MERGL antiserum is highly specific for MERGL, but does show some very slight cross-reactivity with LENK, MENK, MERF, and BAM12P. Giraud et al. ('84) have reported that in RIA this antiserum shows negligible cross-reactivity with other enkephalin peptides. It seems likely that the very slight cross-reactivity of the antiMERGL antiserum with the other enkephalin peptides was immunohistochemically apparent in the present study because the overall levels of labeling for MERGL in the turtle central nervous system were very low. The anti-MERGL antiserum did label neurons and fibers of the rat nervous system intensely, thereby suggesting that the weak labeling of turtle nervous tissue with this antiserum reflects the apparent absence of MERGL in turtle nervous tissue. The anti-BAM22P antiserum showed complete cross-reactivity with Peptide E, but no or little cross-reactivity with dynorphin peptides or the other enkephalin peptides. Thus, the anti-BAM22P antiserum appears to be specific for a portion of the C-terminus of BAM22P common to both BAM22P and PEPE. The anti-PEPE antiserum showed no crossreactivity with any of the dynorphin peptides, but did show cross-reactivity with enkephalin peptides, particularly the longer ones, such as BAM22P (with which it showed nearly complete cross-reactivity) and BAM12P. In addition, the anti-PEPE antiserum showed some slight cross-reactivity with the shorter enkephalin peptides, including LENK, MENK, and MERF. Thus, the anti-PEPE antiserum appeared to be specific for enkephalin peptides, with its greatest binding affinity for the midportion and C-terminus characteristic of PEPE (i.e., PEPE, BAM22P, and BAM12P).

Therefore, of the antisera against the enkephalin peptides used, only Chang's anti-LENK antiserum and the ImmunoNuclear anti-LENK antiserum showed significant cross-reactivity with dynorphin peptides, and in the case of the ImmunoNuclear antiserum, this cross-reactivity was with Dynorphin A(1-8) but not the longer forms of Dynorphin A. Despite the slight cross-reactivity of the ImmunoNuclear antiserum with Dynorphin A(1-8), the labeling pattern obtained with this antiserum was indistinguishable from that obtained with the other antisera against enkephalin peptides. Since the ImmunoNuclear antiserum produced the heaviest labeling of all the antisera used (presumably because of its greater cross-reactivity with other enkephalin peptides), in the presentation of the results below and accompanying line drawings, the distribution of enkephalin is largely based on the ImmunoNuclear anti-LENK antiserum. The cell body distribution is based on the results from colchicine-treated turtles. Colchicine treatment was found to greatly increase perikaryal labeling. It is recognized that the demonstration of labeling with the various anti-LENK antisera used does not necessarily demonstrate the specific presence of LENK in the turtle CNS, since even the highly specific anti-LENK monoclonal antibody cross-reacts with MENK. Nonetheless (as considered further in the Discussion section), intense labeling was observed in the turtle CNS with the ImmunoNuclear antiLENK antiserum even when the antiserum was blocked with MENK. Such results favor the conclusion that LENK is present in the turtle CNS.

The distributions obtained for the various enkephalin peptides were the same, the major differences being in the

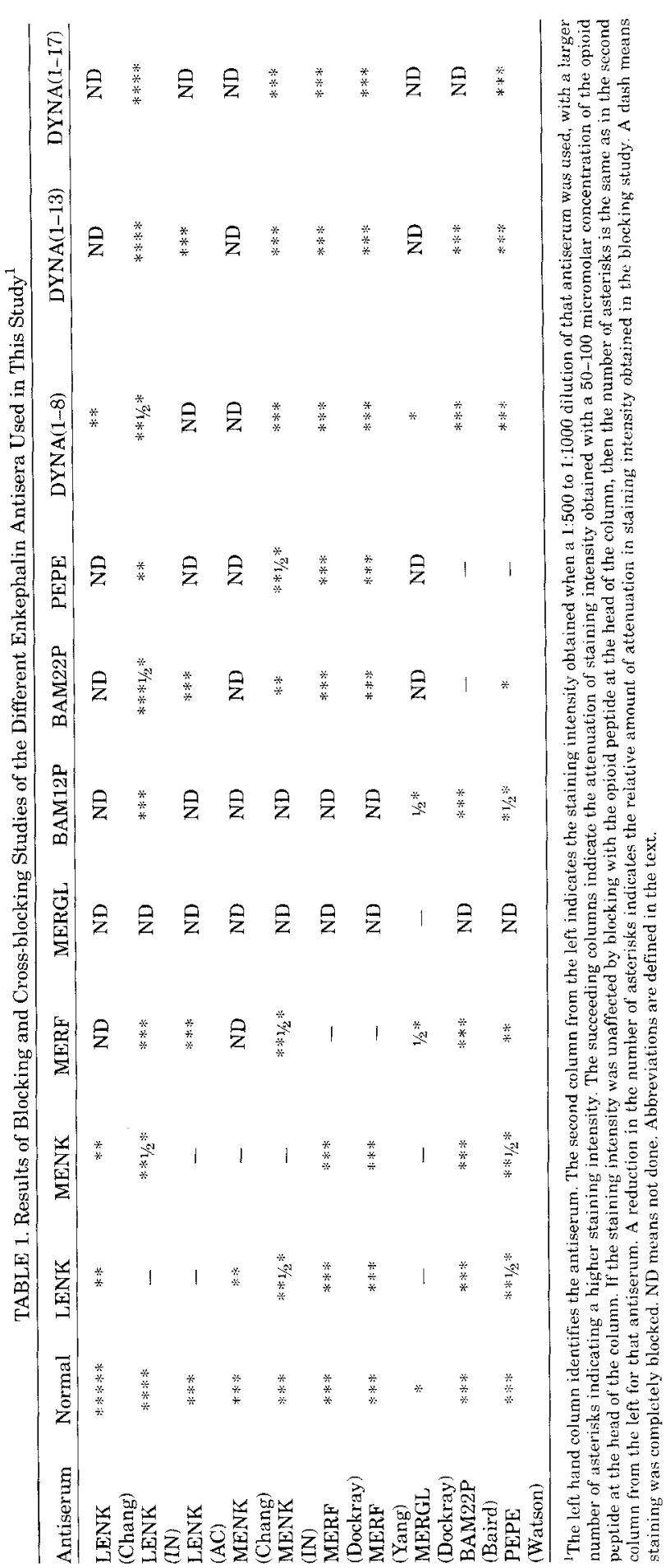


relative intensity with which neurons and fibers in specific regions were labeled by the different antisera. The major characteristics of the labeling obtained with the antiMENK, anti-MERF, anti-MERGL, anti-PEPE, and antiBAM22P antisera are presented subsequent to the description of the anti-LENK labeling pattern. Since the antiMENK, anti-MERF, and anti-MERGL antisera used were largely specific for their target antigens, the labeling patterns observed presumably reflect the distribution of these peptides in the turtle CNS. The anti-BAM22P and antiPEPE antisera are largely specific for a large enkephalin peptide resembling BAM22P and $\mathrm{PEPE}$. The labeling pattern obtained with these antisera presumably reflects the distribution of this peptide (or peptides) in the turtle CNS. Although the anti-MERGL antiserum labeled enkephalinergic neurons well in rats, it produced very little labeling in turtle CNS, and what was observed appeared to be largely cross-reactive labeling of other enkephalin peptides. Thus, MERGL appears to be absent from turtle CNS.

\section{LENK distribution}

Telencephalon. LENK + perikarya were widespread and abundant in the telencephalon of the turtle. The most prominent accumulation of LENK + neurons was observed in the striatal portion of the basal ganglia (Figs. 1-3, see also Fig. 10), which in turtles comprises area $\mathrm{d}$ and the paleostriatum augmentatum (PA). Numerous LENK + neurons were also observed in the "striatallike" cell group, the olfactory tubercle (TuOl) (Fig. 1). Consistent with the abundance of LENK + neurons in the striatum, abundant LENK + fibers were present in the pallidal cell fields of the basal telencephalon (Figs. 2, 3, see also Fig. 10), the globus pallidus (GP) and the ventral paleostriatum (VP), which are comparable to the mammalian globus pallidus and ventral pallidum, respectively (Brauth et al., '83; Reiner et al., '84a). Prominent accumulations of LENK + neurons were also observed in area a (the anterior olfactory nucleus), the septal nuclei (particularly the medial septal nucleus), and a region lateral to the medial amygdaloid nucleus (MA) and dorsal to the nucleus of the lateral olfactory tract (nTOL), which appears comparable to the central amygdaloid nucleus (CA) of mammals (Figs. 1-5). In addition, scattered LENK + neurons were observed in the periventricular portions of the dorsal ventricular ridge (DVR), in the primordium hippocampi $(\mathrm{PH})$, throughout the rostrocaudal extent of all four of the cortical regions of the turtle telencephalon, in the pallial thickening (PT), in the ventral portion of pyriform cortex (cpv), in nTOL, in the basal amygdaloid nucleus (BA), and in MA (Figs. 1-6). Within the olfactory bulb, a few LENK + neurons were present in the mitral cell layer.

LENK + fiber labeling within the telencephalon was most prominent in the GP and VP (Figs. 2, 3, see also Fig. 10). Labeling in the VP, in particular, was denser than in any other brain region. Fiber labeling in the VP and GP appeared to consist of numerous labeled terminals (presumably arising from LENK + striatal neurons) that coated the thick (presumably dendritic) processes of GP and VP neurons. Fiber and terminal labeling was also prominent in the striatum, where the density of the labeled fibers served to demarcate the turtle striatum from the overlying DVR, which contained only scattered LENK + fibers. LENK+ fibers were largely absent from PT and the lateral portion of the dorsal cortex (cd). A dense but lightly labeled accumulation of LENK + fibers that spanned the periventricu- lar, cellular, and deeper two-thirds of the molecular layer of the cortex was present in the medial half of cd as well as in the dorsomedial cortex $(\mathrm{cdm})$ and the medial cortex $(\mathrm{cm})$ (Figs. 2-6, see also Fig. 11). These fibers were more heavily labeled posterior to the interventricular foramen. At all levels, fibers in $\mathrm{cm}$ were more heavily labeled than in $\mathrm{cdm}$ and cd. In addition, a thin band of LENK + fibers was present at the pial surface of $\mathrm{cdm}, \mathrm{cm}$, and medial $\mathrm{cd}$, and also at the pial surface of pyriform cortex (cp), the olfactorecipient cortex (Reiner and Karten, '85). Scattered LENK+ fibers were present in the cell body layer of cp; LENK + fibers were particularly prominent in the ventral subdivision of $\mathrm{cp}$, and were also present in the septal region, BA, MA, CA, and nTOL (Figs. 3-5, see also Fig. 10). Within the olfactory bulb, sparse LENK + fibers were present in the internal granular layer (LGI) and in the layer superficial to the mitral cells. LENK + fibers were also present in area a and nTOL.

Diencephalon. LENK + neurons and fibers were more abundant and more heavily labeled in the hypothalamus than in other portions of the diencephalon. Within the hypothalamus, prominent accumulations of LENK + neurons were present in the preoptic region, the periventricular hypothalamus (nPH), the ventromedial hypothalamus (nVH), the medial hypothalamus ( $\mathrm{nMH}$ ), and the lateral hypothalamus (Figs. 2-5). Within the preoptic region, LENK + cells gave rise to processes that penetrated the ependymal wall of the ventricle and appeared to be in contact with the ventricular cavity (see Fig. 11). LENK+ cells were found in $\mathrm{nPH}$ throughout the entire length of the hypothalamus. LENK + neurons were also present in the mamillary region, tuberal region, and in the neurohypophysis (NHy). LENK + fibers were present throughout the hypothalamus, but more highly concentrated medially than laterally. The $\mathrm{nVH}$ contained a dense accumulation of fine LENK + fibers that defined the extent of nVH (Fig. 12). LENK + neurons of nVH tended to be located at the peripheral edges of this cell group. LENK + fibers were also present in the median eminence (ME) and the neurohypophysis.

Within the epithalamus, LENK + neurons and fibers were present in more lateral portions of the medial habenular nucleus (HM), and LENK + fibers were present in the lateral habenular nucleus (HL) (Figs. 4, 5, see also Fig. 12). Within the thalamus, nucleus rotundus $(R)$ and the core of nucleus reuniens $(\mathrm{Re})$ were devoid of LENK + fibers and neurons (Figs. 4, 5, see also Fig. 12). These cell groups are involved in the processing of visual and auditory input and project to separate regions of the DVR (Hall and Ebner, '70; Reiner and Powers, '78, '80, '83; Balaban and Ulinski, ' $81 \mathrm{a}, \mathrm{b})$. The retinorecipient cell group, the dorsal lateral geniculate (GLd), which projects to cd and PT, is also largely devoid of LENK + fibers and contains only a few LENK + neurons. Nucleus ventralis (nV), an apparent somatosensory relay nucleus of the thalamus (Hall et al., '77; Kunzle and Woodson, ' 82 ), is largely devoid of LENK + fibers and contains no LENK + neurons. In contrast, abundant LENK + fibers were observed in the nonspecific projection nuclei of the turtle thalamus, the dorsolateral (DLA), and the dorsomedial anterior nuclei (DMA) (Figs. 4, 5, see also Fig. 12). These cell groups, however, were rarely observed to contain LEN]K + neurons. Within the ventral thalamus, the diencephalic region interposed between thalamus and hypothalamus, scattered LENK + neurons and fibers were observed.

Midbrain. Prominent numbers of LENK + neurons were observed in several regions of the midbrain, including the 

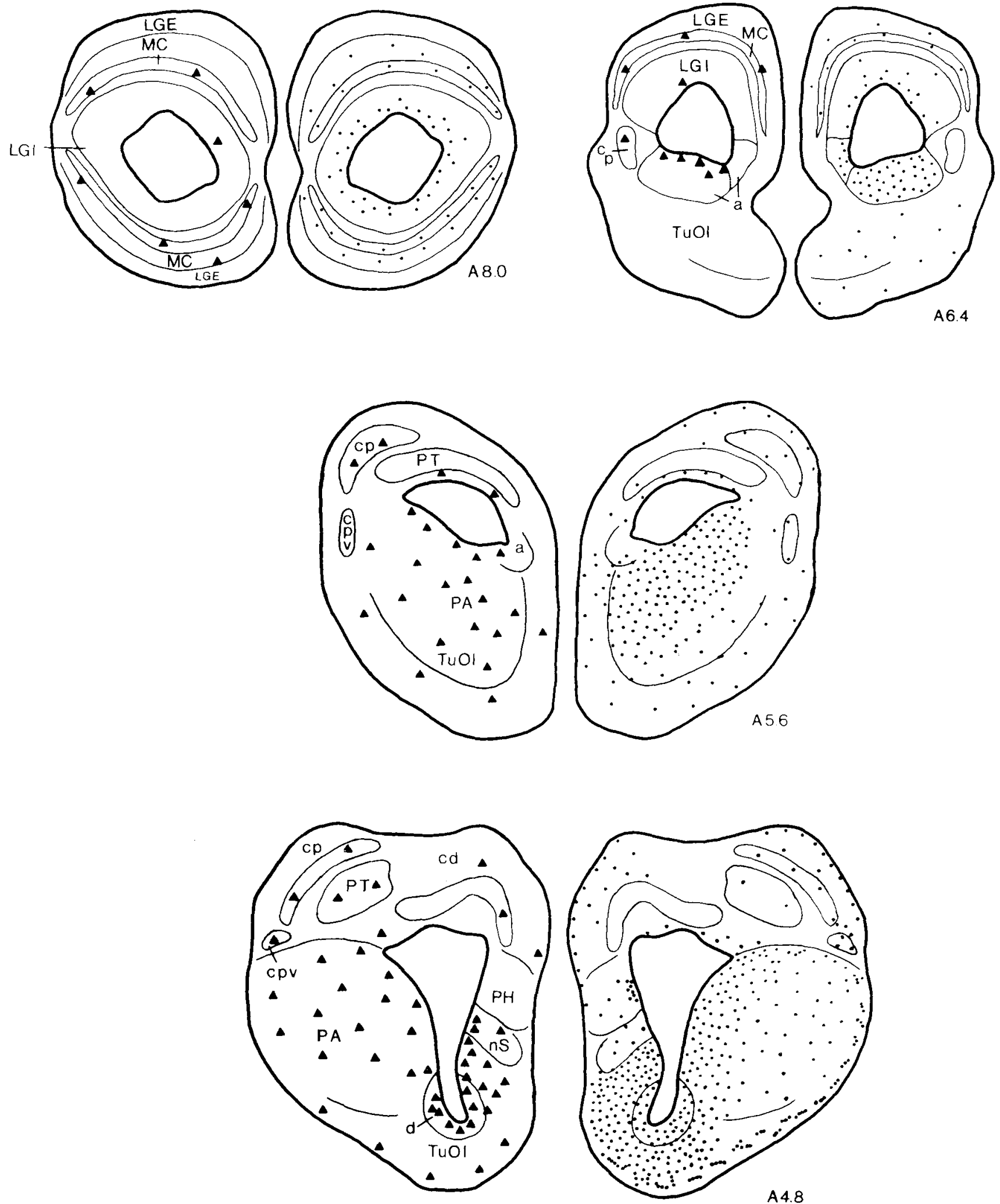

Fig. 1. Line drawings of transverse sections through turtle olfactory bulb and rostral telencephalon illustrating the location and relative density of LENK + fibers and terminals (dots), as shown on the right side of each drawing, and perikarya (triangles), as shown on the left side of each drawing, observed with immunohistochemical procedures. Each triangle corresponds to 1-5 LENK + neurons. The numbers to the lower right indicate the anterior-posterior level of the section in stereotaxic coordinates. 

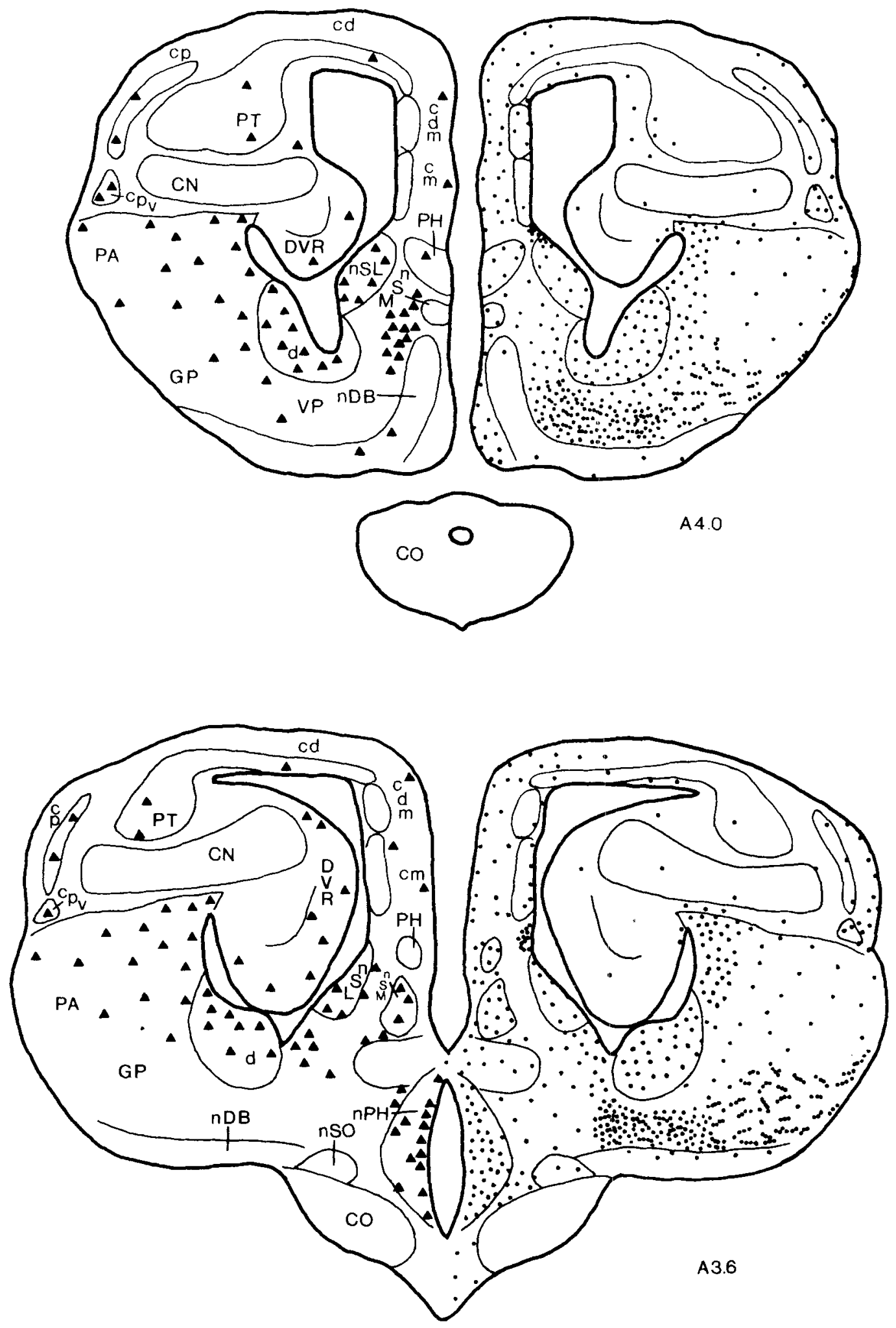

Fig. 2. Line drawings of transverse sections through slightly more caudal telencephalic levels of turtle brain than shown in Figure 1. Dots and triangles in Figures 2-9 indicate the relative density of LENK + fibers and perikarya, respectively, observed with immunohistochemical methods. 

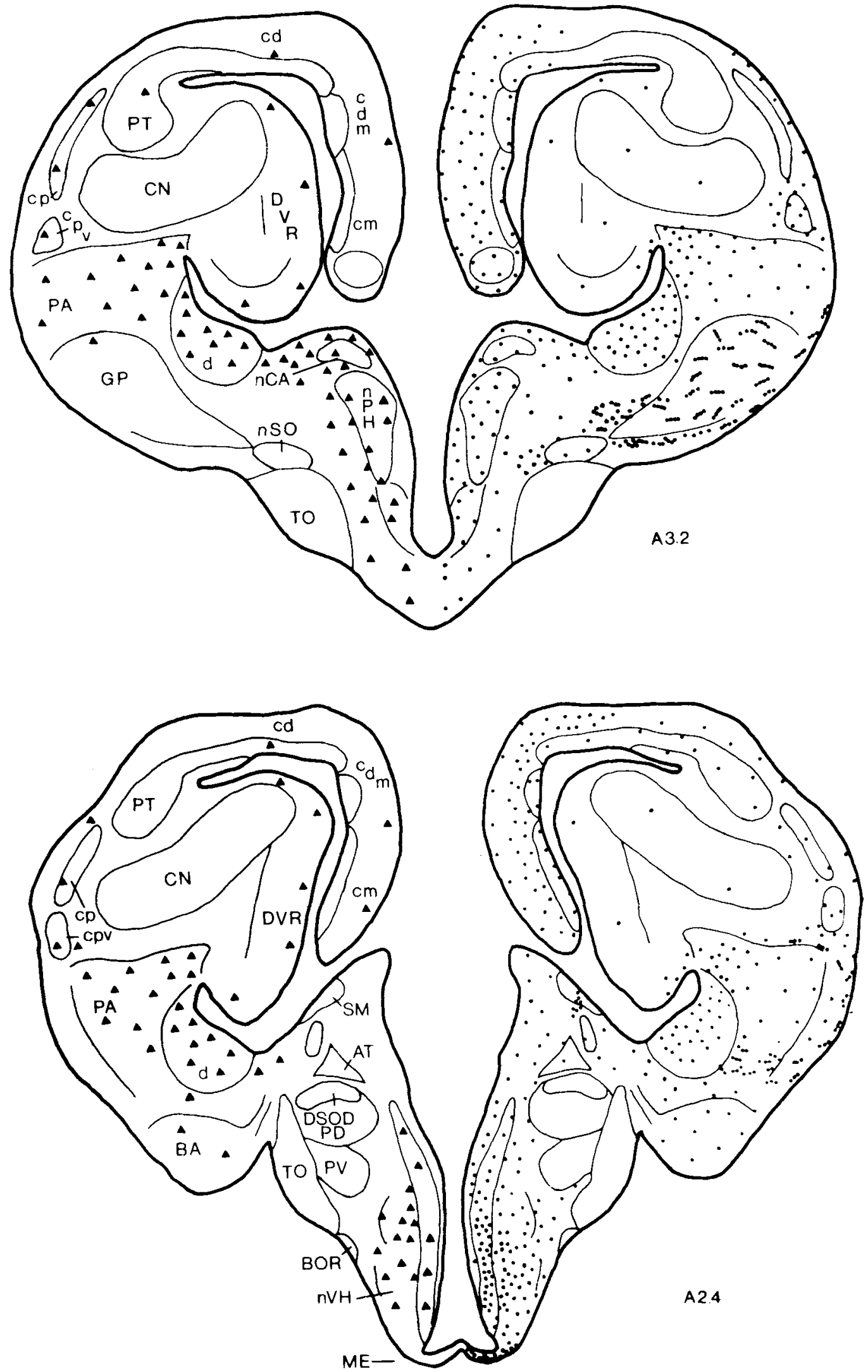

Fig. 3. Line drawings of transverse sections through the midtelencephalon and rostral diencephalon of turtle showing the distribution of LENK + fibers, terminals, and perikarya. 

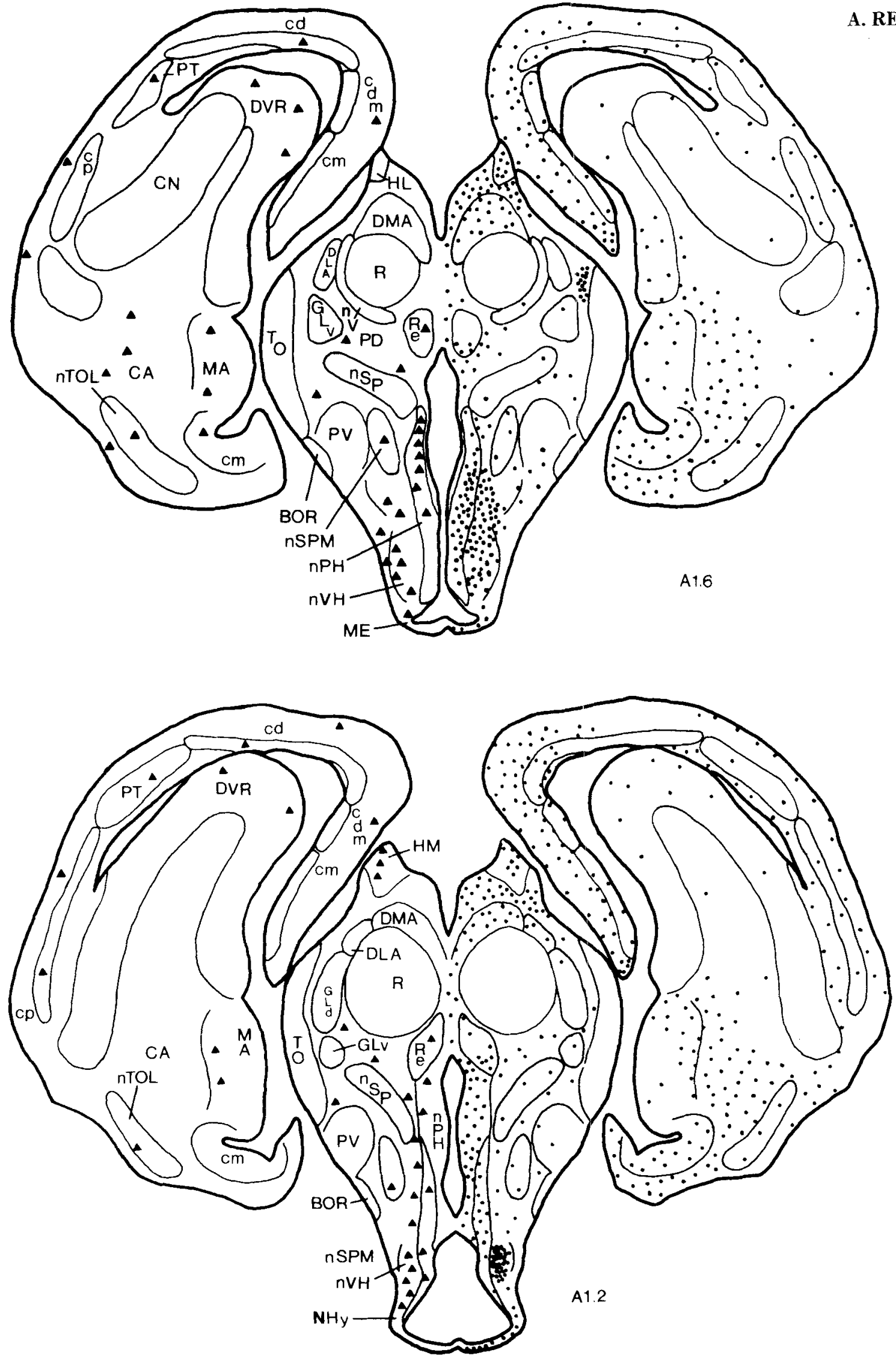

Fig. 4. Line drawings of transverse sections through the caudal telencephalon and middiencephalon of turtle showing the distribution of LENK + fibers, terminals, and perikarya. 

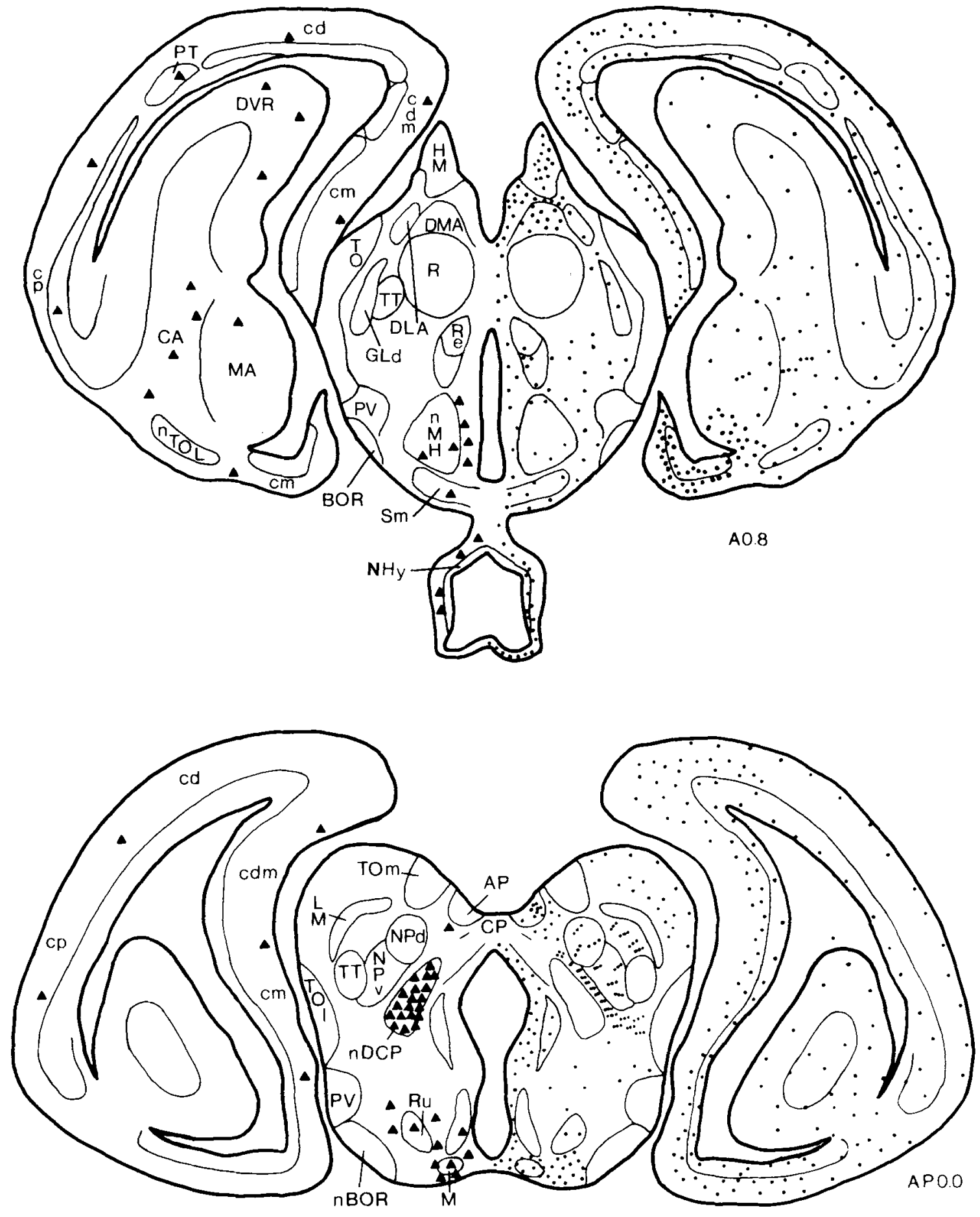

Fig. 5. Line drawings of transverse sections through the caudal telencephalon and mesodiencephalic junctional region of turtle showing the distribution of LENK + fibers, terminals, and perikarya.

dorsal nucleus of the posterior commissure (nDCP) of the pretectum, the medial tegmentum, the laminar nucleus (La) of the torus semicircularis (TSC), and the stratum griseum periventriculare (SGP) of the tectum (Figs. 5, 6, see also Fig. 12). Fiber labeling in the tegmentum was generally light, consisting of scattered LENK + fiberswith a somewhat greater accumulation of fibers in the medial tegmental (including AVT and the peri-interpeduncular region). LENK + fibers were abundant in La and in the periventricular portions of the midbrain. Within area pretectalis (AP), a dense patch of coarse LENK + fibers and a few LENK + cells were observed (Fig. 5). Thick processes that appeared to be the processes of the LENK + nDCP cells were observed to fan out from $\mathrm{nDCP}$, pass through and 

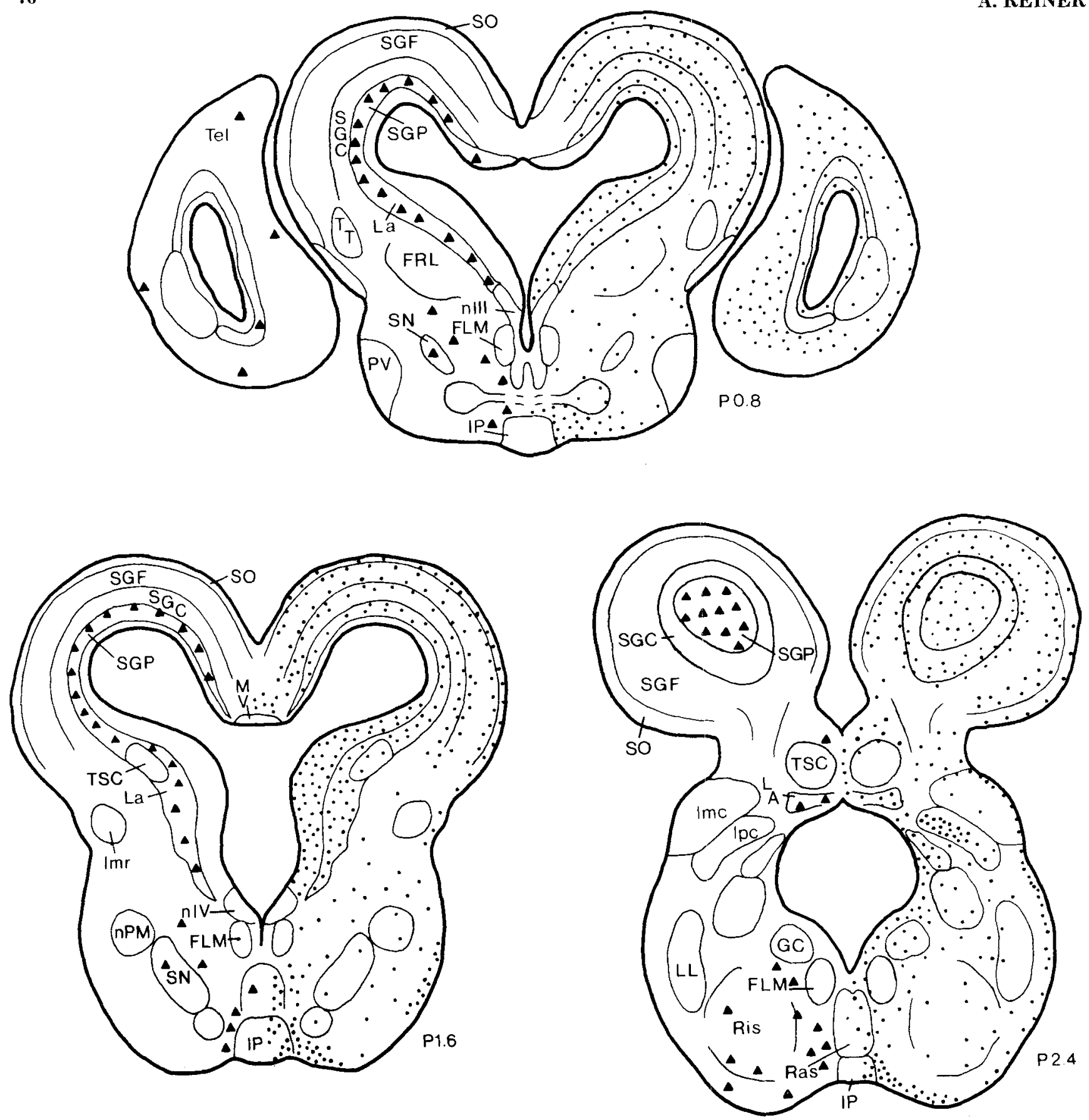

Fig. 6. Line drawings of transverse sections through the midbrain of turtle showing the distribution of LENK + fibers, terminals, and perikarya.

around the adjacent pretectal nuclei, and enter the tectum from its rostral, medial, and lateral edges (Fig. 5, see also Fig. 12). Within the tectum, these fibers were observed to course in the stratum album centrale (SAC) and ramify into more superficial and deeper tectal layers. Within the optic tectum (TeO), LENK + fibers were abundant and continuously distributed throughout the deep fiber (SAP) and gray (SGP) layers, in the central fiber (SAC) and gray (SGC) layers, and in the deeper (nonretinorecipient) half of the superficial gray and fiber layer (SGF) (Fig. 6, see also Fig. 12). LENK + fibers were also evident in two separate bands in the superficial (retinorecipient) half of SGF. The more superficial of these was located immediately deep to the stratum opticum (SO) and appeared to consist of coarse LENK + fibers. This superficial band is separated from the deeper LENK + band of the retinorecipient tectum by a zone that was relatively free of LENK + fibers. The deeper retinorecipient band consists of numerous thin radially oriented LENK + fibers that give rise to ramifications within the band parallel to the pial surface. This band of fibers, which coincides with the densest retinorecipient zone of the turtle tectum (Bass and Northcutt, ' 81 ), is separated from 
ENKEPHALIN IN TURTLE CNS
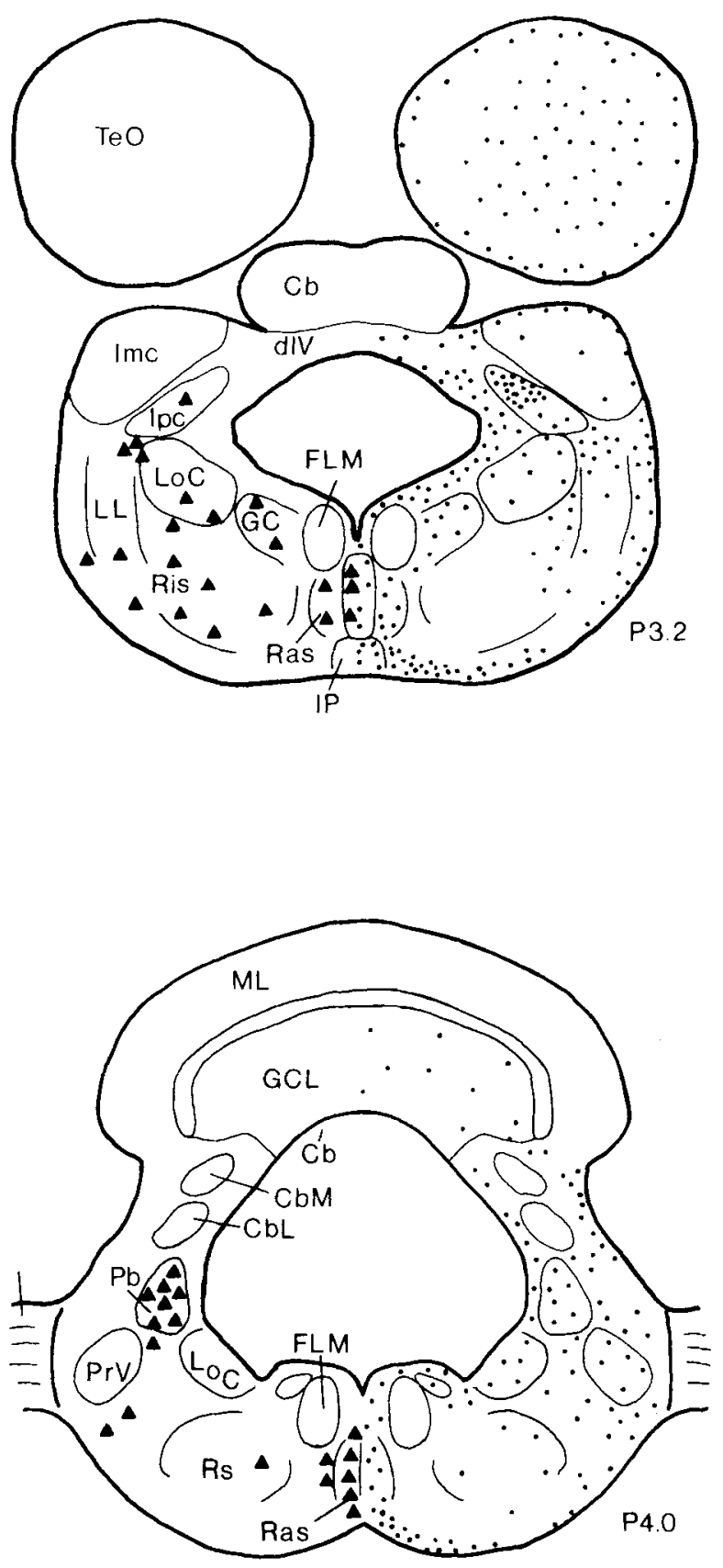

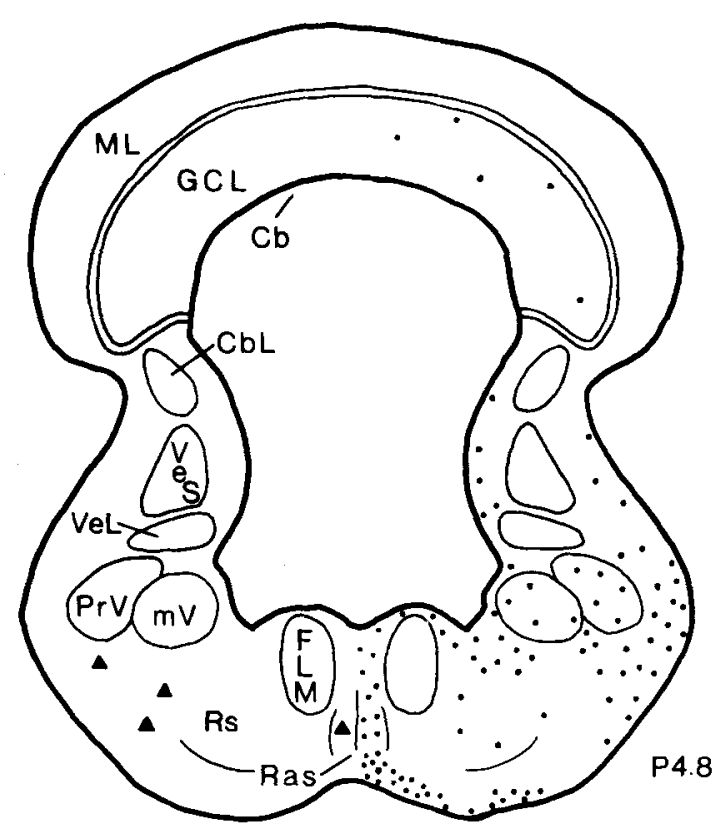

Fig. 7. Line drawings of transverse sections through the rostral rhombencephalon of turtle illustrating the distribution of LENK + fibers, terminals, and perikarya.

deeper LENK + fibers by a zone that is relatively poor in LENK + fibers.

Rhombencephalon. Within the rostral (or isthmic) portions of the hindbrain, several cell groups containing prominent populations of LENK + neurons were observed, including the parabrachial region $(\mathrm{Pb})$, the superior raphe (Ras), the nucleus of the lateral lemniscus, the lateral isthmic reticular formation (Ris), and a cell group along the lateral edge of the parvocellular isthmic nucleus (Ipc) (Fig. 7). The latter appears to be the enkephalinergic cell group reported to give rise to centrifugal projections to the retina of the contralateral eye, as recently described by Weiler ('85). LENK + fiber labeling within the isthmus was prominent in periventricular regions, lateral to and within Ras, within medial Ipc, in the peri-interpeduncular region, and along the ventromedial floor of the brainstem. LENK+ fibers were also evident in the central gray (GC), the locus coeruleus (LoC), and surrounding the lateral lemniscus (LL). LENK + fibers were scarce in Ris and in both subdivisions (rostral and caudal) of the magnocellular isthmic nucleus, although the dorsolateral rim of the magnocellular isthmic nucleus did contain prominent LENK + fibers. 
Within the metencephalon, scattered LENK + fibers, which appeared to be mossy fibers, were present in the GCL of the $\mathrm{Cb}$ (see Fig. 13). LENK + fibers in GCL were more abundant in caudal $\mathrm{Cb}$ than rostral (Figs. 7, 8). Within the pons, LENK + cells were observed in the lateral portions of the superior (Rs) and medial reticular formation (Rm). LENK + fibers were present in Ras, in the ventromedial pons, and in the motor and sensory cell groups of the trigeminal nerve. Within the lateral pontine regions, heavily labeled LENK + terminals and fibers coated neurons of the motor nucleus of the trigeminal nerve (MV) (Fig. 7, see also Fig. 13), and a dense accumulation of LENK + fibers was present along the pial surface lateral to the descending tract of the trigeminal nerve (TTd) (Figs. 7, 8, 9). At caudal pontine levels, LENK + neurons were present between TTd and the motor nucleus of the facial nerve (nVII), and numerous neurons were present in lateral Rm (Figs. 8, 9). Sparse LENK + fibers were present in the cochlear nuclei.

Within the medulla, LENK + neurons were present in the nucleus of the solitary tract (nTS), in the descending vestibular nucleus (VeD), in lateral intermediate reticular formation ( $\mathrm{Ri}$ ), in the motor nucleus of the vagus nerve (nX), in the motor nucleus of the hypoglossal nerve (nXII), and in the area lateral to caudal TTd (Figs. 8, 9). Within the spinal cord, LENK + neurons were present in Lissaur's zone (along the pial surface of the dorsal root entry zone), in the dorsal horn, and in the intermediate gray of the cord (Figs. 9, 13). LENK + neurons were also observed-but only rarely-in the ventral horn. LENK + fiber labeling in the medulla was most prominent in the ventrolateral quadrant of the brainstem. A region of dense LENK + fibers was present along the pial surface lateral to TTd. This zone of labeling was continuous with the similar zone in the dorsal root entry zone of the spinal cord (Figs. 8, 9). Within the medulla, LENK + fibers were also present in nTS, the intermediate raphe (Rai), nVII, $\mathrm{nX}$, and $\mathrm{nXII}$. Within $\mathrm{nVII}$, LENK + fibers and terminals appeared to coat large unlabeled neurons (Fig. 8). LENK + fibers were also observed along the ventromedial floor of the medulla; the labeled fibers were continuous with fibers of a similar appearance and location in the pons. Within the spinal cord, LENK+ fiber labeling was most prominent in Lissauer's zone, and less dense accumulations of fibers were present in the dorsal horn and dorsal portions of the lateral funiculus. LENK + fibers were also present in the ventral horn (Figs. $9,13)$.

\section{MENK distribution}

The labeling pattern with each of the two MENK antisera was virtually indistinguishable from that observed with the LENK antisera. Both LENK and MENK antisera labeled neurons in the same cell groups, although the MENK antisera consistently labeled fewer neurons. Similarly, although the fiber labeling patterns were indistinguishable, MENK + fibers tended to be more lightly labeled, even when higher concentrations of the MENK antisera than the LENK antisera were used.

\section{MERF distribution}

The MERF labeling pattern was the same for both antiMERF antisera and was indistinguishable from the LENK + pattern, except that the labeled neurons and fibers tended to be more lightly labeled and fewer in number than for the anti-LENK antisera. Nonetheless, labeled neurons and fibers were observed in the same cell groups with both the anti-MERF' and anti-LENK antisera. 'The most conspicuous regions where MERF + neurons and fibers were fewer in number and more lightly labeled were PA, cp, cpv, cdm, and $\mathrm{cm}$.

\section{PEPE/BAM22P distribution}

Since the anti-PEPE and anti-BAM22P antisera showed nearly complete (anti-PEPE) or complete (anti-BAM22P) cross-reactivity with each other's antigens, the results for the two antisera are presented together. PEPE/BAM22P+ neurons and fibers were observed in the same cell groups as were LENK+ neurons and fibers. Although PEPE/ BAM22P + labeling of neurons and fibers in many of these cell groups was less intense than for LENK, many other groups contained neurons and fibers that labeled more heavily for PEJPE/BAM22P. In particular, neurons of ventromedial area $d$, the nucleus of the anterior commissure (nCA), and regions near nCA were very PEPE/BAM22P+. Both the cell bodies and dendrites were heavily labeled. LENK + neurons in these regions showed lighter perikaryal labeling and little dendritic labeling. In contrast, neurons of PA were more heavily labeled for LENK than for PEPE/BAM22P; similarly, within the hypothalamus and in nDCP, neurons were more heavily labeled for LENK. Fiber labeling for PEPE/BAM22P was heavy in the VP, but much lighter in GP. This is consistent with the finding that medial striatal cells (i.e., area $\mathrm{d}$ and medial PA), which presumably project to VP, are more heavily labeled for PEPE/ BAM22P than lateral striatal cells (i.e., lateral PA), which project to GP. Although the MENK, MERF, and PEPE/ BAM22P labeling patterns were highly similar to that obtained for LENK, the overall number of neurons labeled with PEPE/BAM22P was much greater than for MENK and MERF.

\section{MERGL distribution}

Only extremely light labeling was obtained with the antiMERGL antiserum, and it was restricted to the regions most heavily labeled by the other enkephalin antisera. In addition, the low level of labeling could be blocked or greatly attenuated with other enkephalin peptides (see Table 1). Thus, MERGL appears to be absent from the turtle central nervous system.

\section{Double-label studies}

The simultaneous immunofluorescence technique was used to study the colocalization of LENK and MERF (using Dockray's antiserum) and the colocalization of LENK and BAM22P. LENK and MENK colocalization was not examined because the complete cross-reactivity of the monoclonal anti-LENK antibody with MENK rendered LENKMENK colocalization studies with these antisera meaningless. LENK and PEPE colocalization studies were not carried out because the anti-PEPE and anti-BAM22P antisera have similar specificities. The anti-BAM22P, rather than the anti-PEPE, antiserum was used because it cross-reacts much less with other enkephalin peptides.

In the cell groups examined (area d, nCA, nPH, $\mathrm{nDCP}$, the preoptic area, the mamillary region, and Lissauer's tract), neurons that contained LENK also contained BAM22P and MERF (Figs. 14, 15). In the regions examined, essentially all fibers examined that contained LENK also contained BAM22P and MERF, although these fibers tended to be much more lightly labeled for the latter two. 

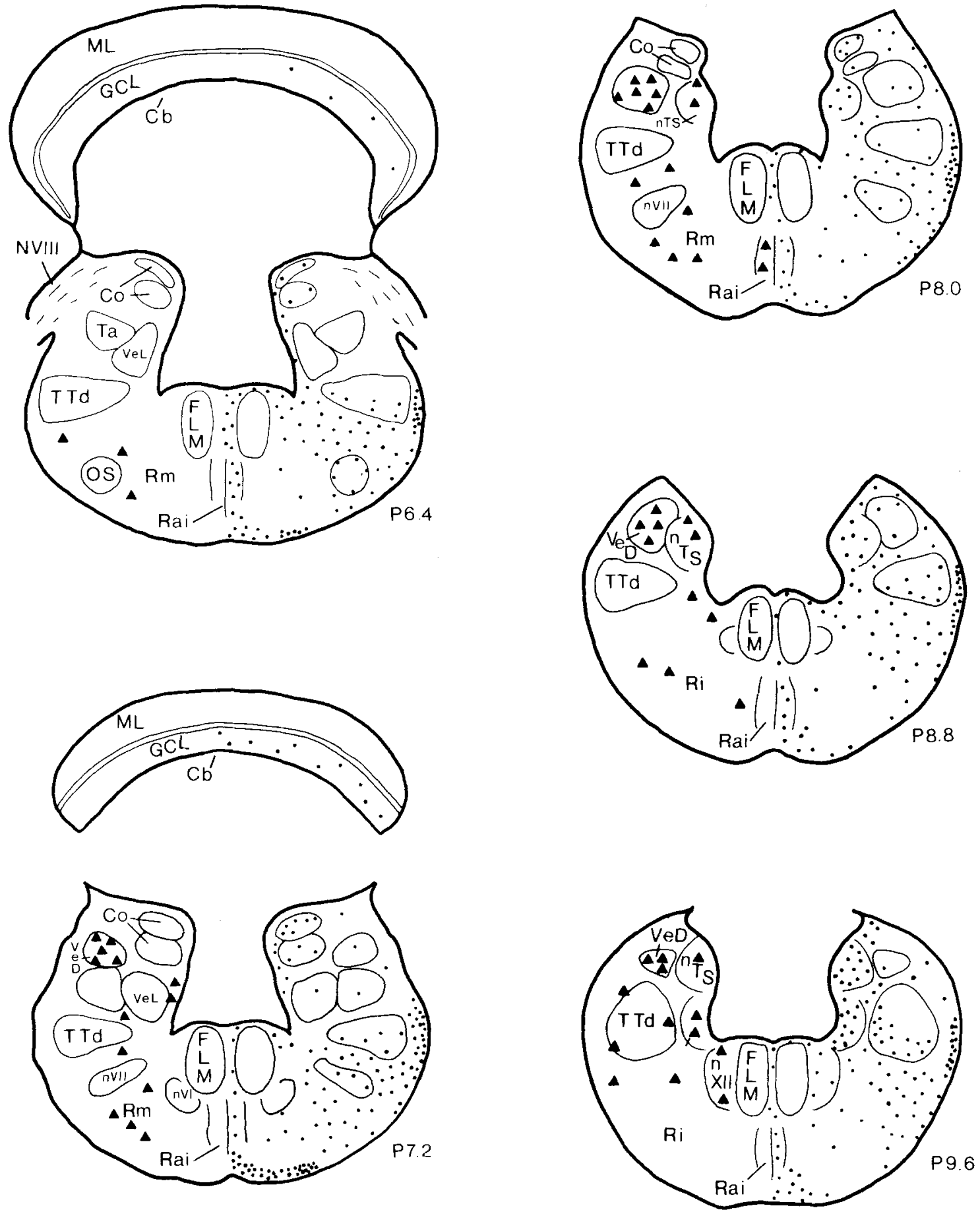

Fig. 8. Line drawings of transverse sections through the caudal rhombencephalon of turtle illustrating the distribution of LiENK + fibers, terminals, and perikarya.

\section{DISCUSSION}

The present studies demonstrate that peptides highly similar or identical to several of the major opioid peptide products derived from mammalian proenkephalin are present in the turtle central nervous system. These peptides include LENK, MENK, MERF, and PEPE/BAM22. All four (or similar peptides) are widely distributed and present in many neurons and fibers of the turtle CNS. Further, the distributions for these four substances are indistinguishable, and colocalization studies revealed that LENK, MERF, and PEPE/BAM22P are found in the same neurons. Although colocalization studies were were not carried out using the anti-MENK antisera, present results strongly suggest that MENK is also present in neurons that contain LENK, MERF, and PEPE/BAM22P. This argument is based on the similarities in distribution between MENK and the other enkephalin peptides and on the observation that all 

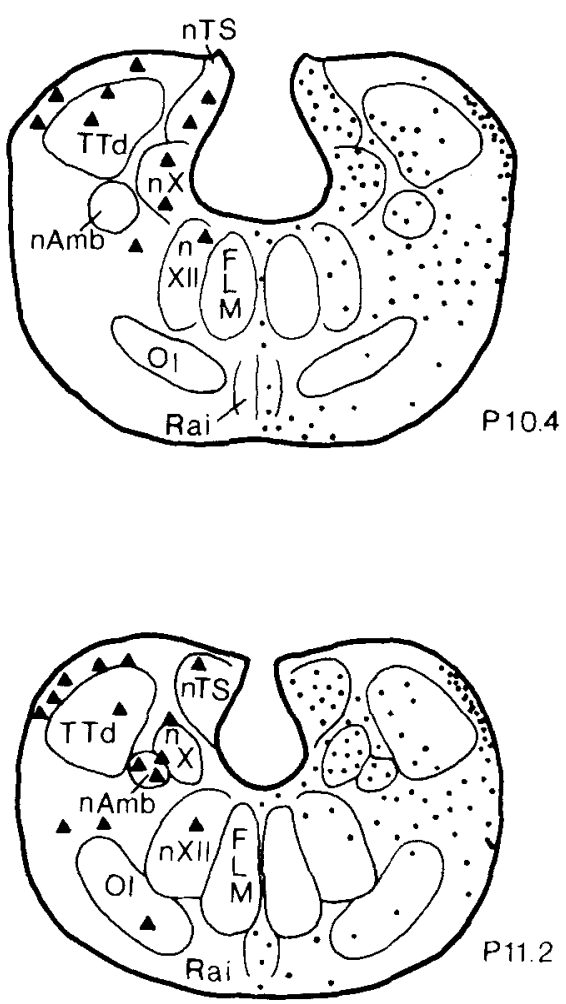

Fig. 9. Line drawings of transverse sections through the spinomedullary junction and the spinal cord in turtle illustrating the distribution of LENK + fibers, terminals, and perikarya.

neurons of nDCP could be labeled for MENK (even when the anti-MENK antisera were blocked with LENK), as well as for LENK, MERF, and PEPE/BAM22P. Therefore, it seems likely that a proenkephalinlike peptide is synthesized by neurons in turtles, and this precursor contains regions whose amino acid sequences are highly similar or identical to LENK, MENK, PEPE/BAM22P, and MERF. The labeling obtained with anti-MERGL in the present study was extremely light and blockable by various enkephalin peptides, implying that turtle proenkephalin does not contain a region resembling MERGL, or that a MERGLlike region is present but sufficiently different in amino acid sequence as to render it noncross-reactive with the antiserum used here. A recent radioimmunoassay and high performance liquid chromatography (HPLC) study on the reptilian nervous system (Lindberg and White, '86) supports the conclusion that the LENK-like, MENK-like, and MERF-like substances detected in the turtle central nervous system in the present study are, in fact, LENK, MENK, and MERF. This study also found no evidence for the presence of MERGL in the turtle nervous system (Lind berg and White, ' 86 ).
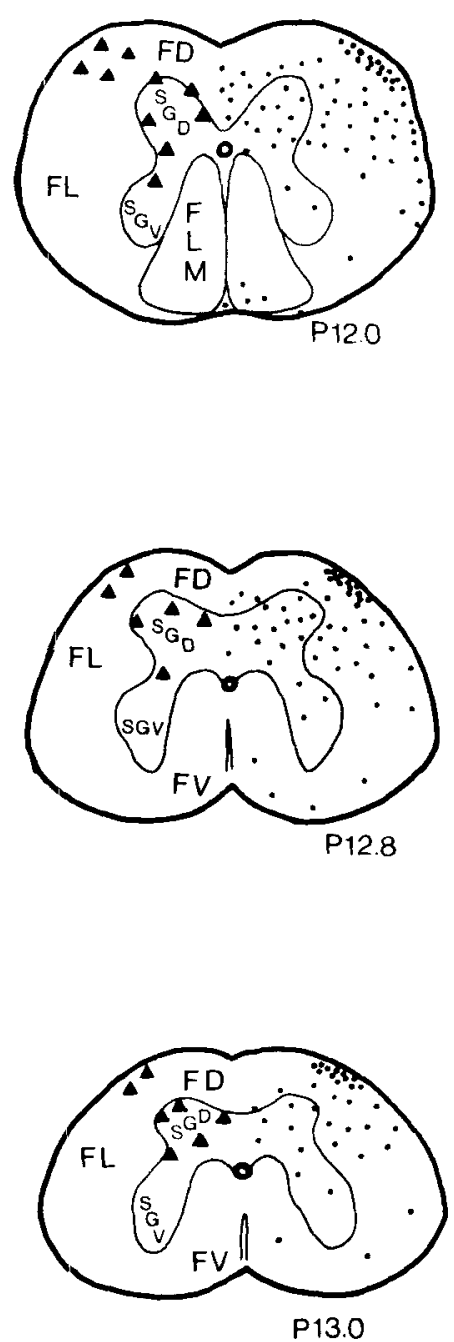

\section{Structure of turtle proenkephalin and the evolution of proenkephalin}

Recently, Herbert and coworkers (Martens and Herbert, '84; Herbert et al., ' 85 ) determined the structure of proenkephalin in Xenopus using cDNA cloning technology. They found that Xenopus proenkephalin possessed no copies of LENK and five copies of MENK, instead of one copy of LENK and four of MENK as in proenkephalin in mammals. In addition, the MERF sequence was present in Xenopus proenkephalin, but the MERGL sequence was not. A MERGL-like sequence, in which the last amino acid has been replaced by tyrosine and which does not cross-react with antisera specific for MERGL, however, is present in Xenopus (Martens and Herbert, '84). Kilpatrick et al. ('83) used HPLC and RIA (using highly specific antisera) to study Rana pipiens central nervous system and confirmed the findings of Herbert and coworkers (Martens and Herbert, '84; Herbert et al., '85) that MERGL appeared to be absent in frogs, but reported that LENK, as well as MENK and MERF, were present. Although the ratio of MENK to MERF levels was about 4:1 (as in mammals), the ratio of 

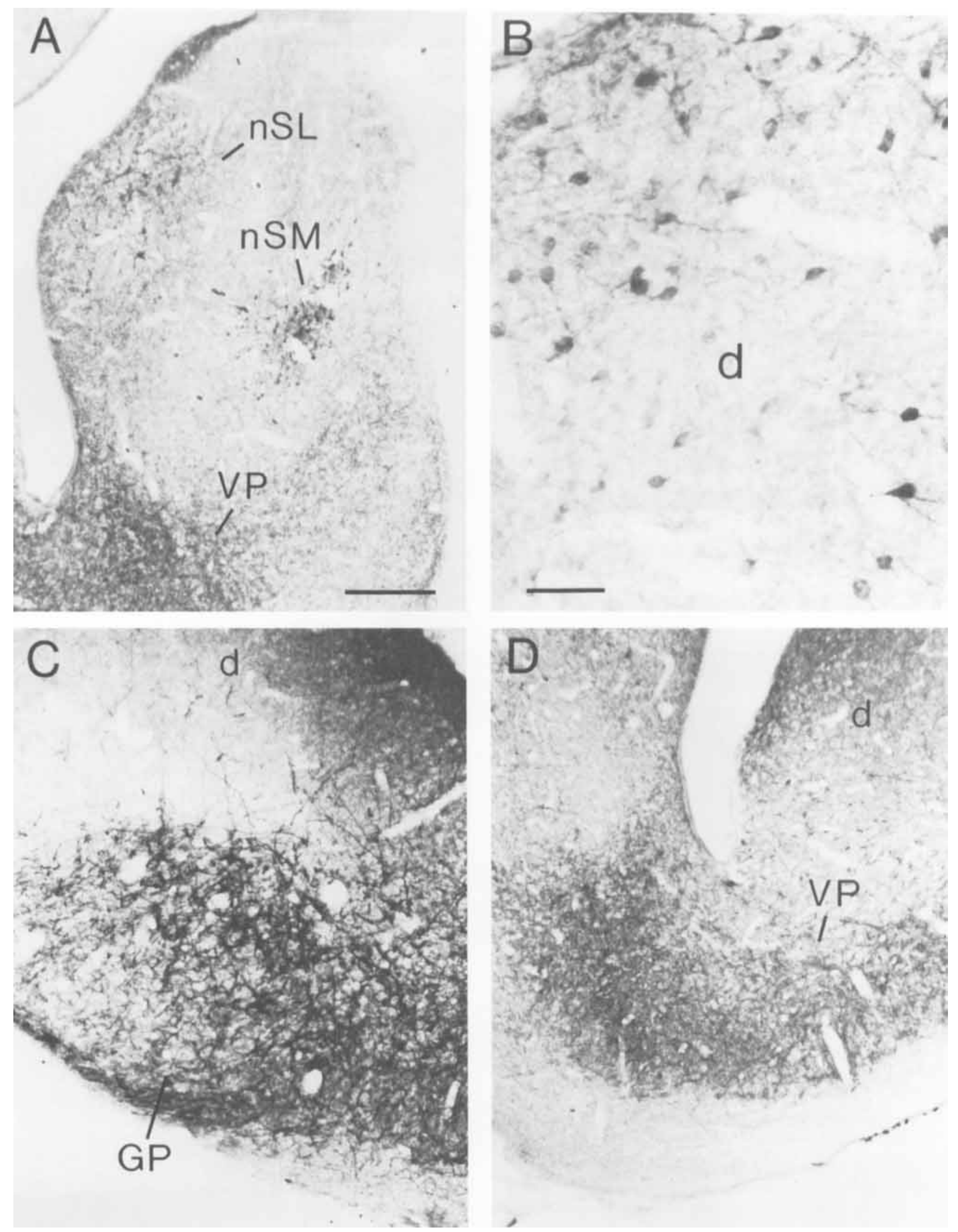

Fig. 10. Photomicrographs of labeling in PAP-stained transverse sections through the turtle brain. A. LENK + fiber and terminal labeling in the septal region (medial to the right). B. PEPE + perikaryal labeling in area d

pallidus of the basal ganglia (medial to the right). D. LENK + fiber labeling in the ventral paleostriatum, a pallidal portion of the basal telencephalon (medial to the left). Scale bars: A,C,D (same magnification) $=250$ microns, of the striatum (medial to the left). C. LENK + fiber labeling in the globus 

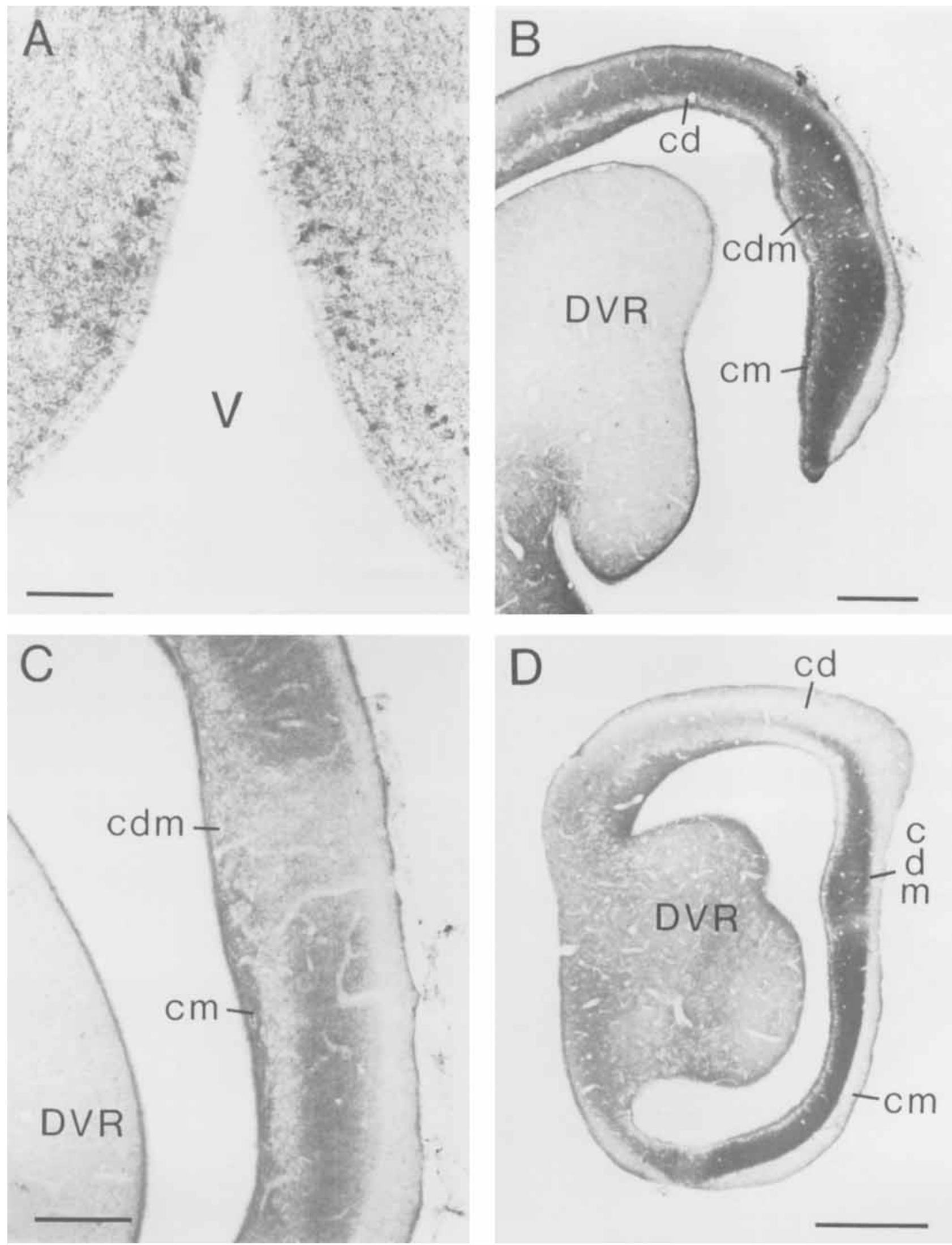

Fig. 11. Photomicrographs of LENK + labeling in PAP-stained transverse sections through the turtle brain. A. LENK + perikarya with labeled processes extending through the ependymal lining of the ventricle. $\mathbf{B}$. LENK + fiber labeling in the medial half of the cortex (medial to the right). C. A more high-power view of the LENK + fiber labeling in the medial half

of the cortex comparing the labeling pattern in $\mathrm{cm}$ and $\mathrm{cdm}$ (medial to the right). D. The fiber labeling pattern in the medial half of the cortex at caudal telencephalic levels (medial is to the right). Scale bars: $A=100$ microns, $\mathrm{B}=500$ microns, $\mathrm{C}=250$ microns, $\mathrm{D}=1,000$ microns. 

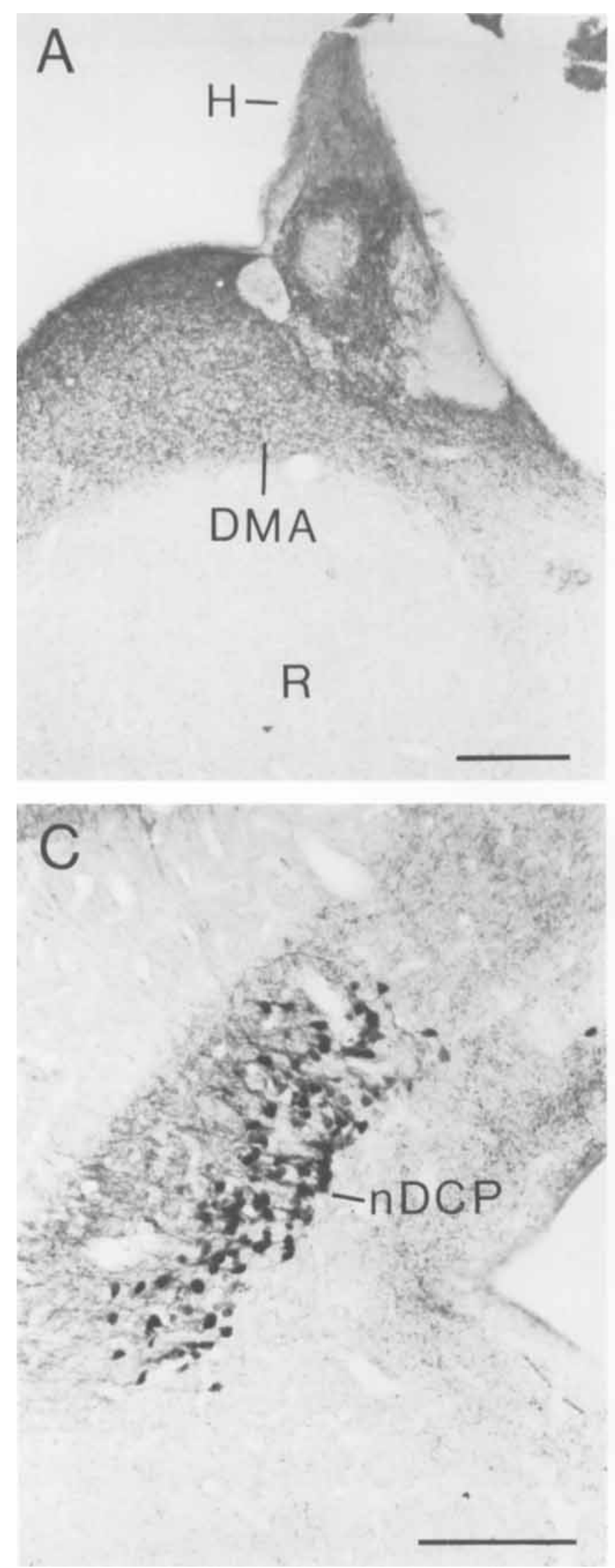
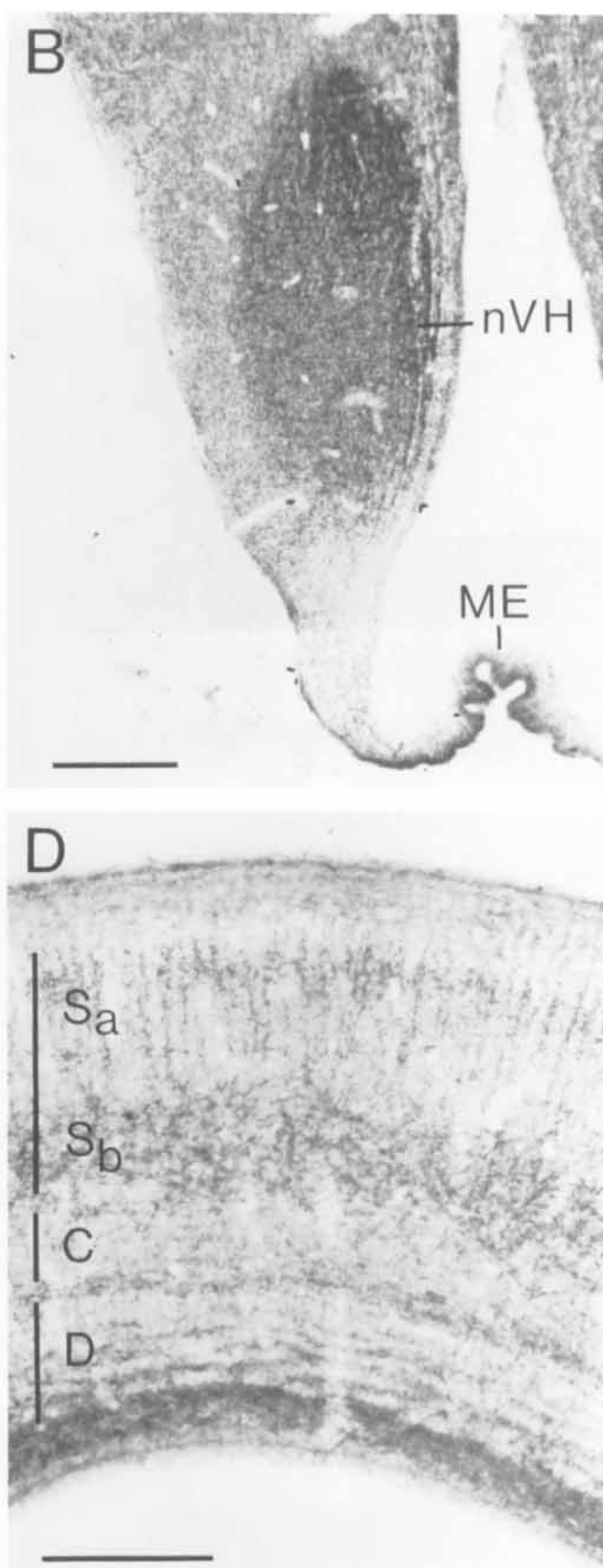

Fig. 12. Photomicrographs of LENK + labeling in PAP-stained transverse sections through the turtle brain. A. LENK + fiber labeling in the epithalamus and dorsal portions of the thalamus (medial to the left). B. LENK + fiber labeling in the hypothalamus at the level of $\mathrm{nVH}$ (medial to the right). C. LENK + perikaryal labeling in nDCP of the pretectum (medial to the right). D. LENK + fiber labeling in the tectum ( $\mathrm{Sa}$, retinorecipient portion of SGF; Sb, nonretinorecipient portion of SGF; C, SGC; D, SGP). Scale bars: $A, B=250$ microns, $C, D=200$ microns. 

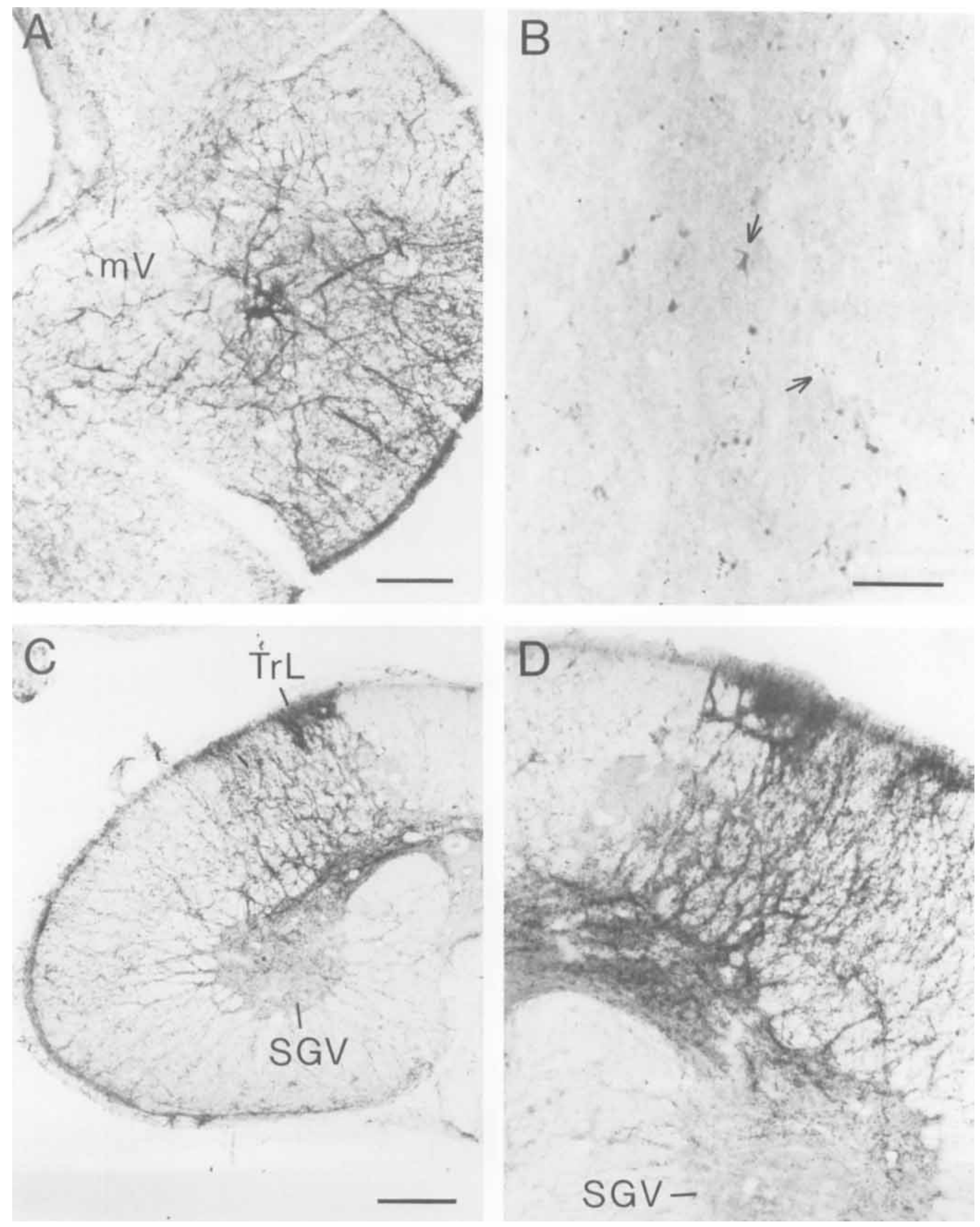

Fig. 13. Photomicrographs of LENK + labeling in PAP-stained transverse sections through the turtle brain and spinal cord. A. LENK + fiber labeling in the ventrolateral rhombencephalon at the level of the motor nucleus of the trigeminal nerve $(\mathrm{mV})$. B. LENK + fibers in the cerebellum. C. LENK + fiber labeling in the cervical spinal cord. D. A more high-power view of LENK + fiber labeling in the dorsal horn of the spinal cord. Scale bars: $A=100$ microns, $B=50$ mierons, $C=200$ microns. 

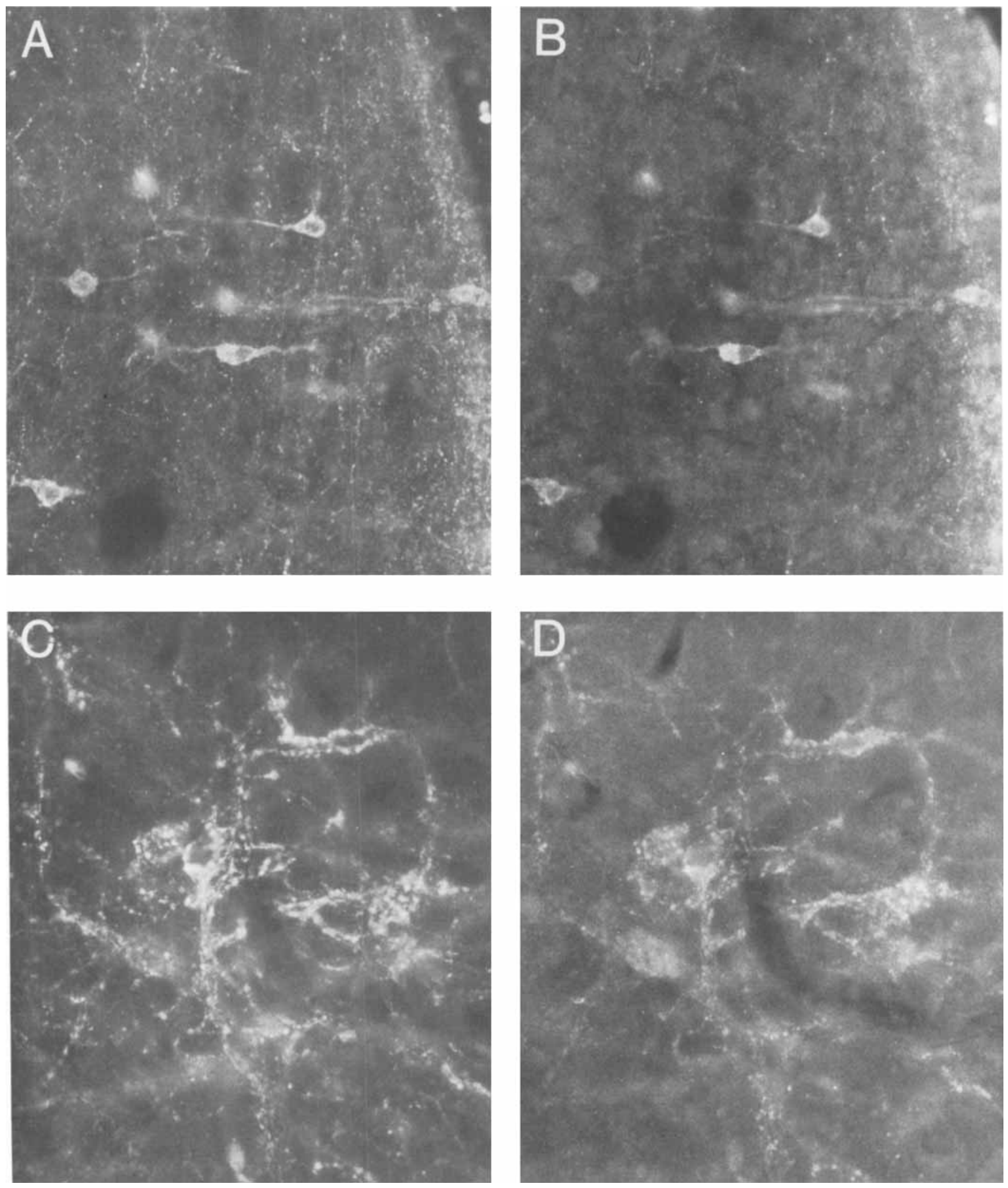

Fig. 14. Pairs of photomicrographs of two transverse sections through the turtle brain that had been processed according to the simultaneous immunofluorescence procedure for the colocalization of LENK and MERF.

A. LENK + FITC-labeled perikarya and fibers in a single field of view through the rostral periventricular hypothalamic region. B. MERF + TRITClabeled perikarya and fibers present in this same field of view. Note that

the same perikarya are labeled for both LENK and MERF. Medial is to the right in A and B. C. LENK + FITC-labeled fibers and terminals in a single field of view through the ventrolateral rhombencephalon near the facial nucleus. D. MERF + TRITC-labeled fibers and terminals present in this same field of view. Note that the same fibers and terminals are labeled for both LENK and MERF. Medial is to the left in C and D. 

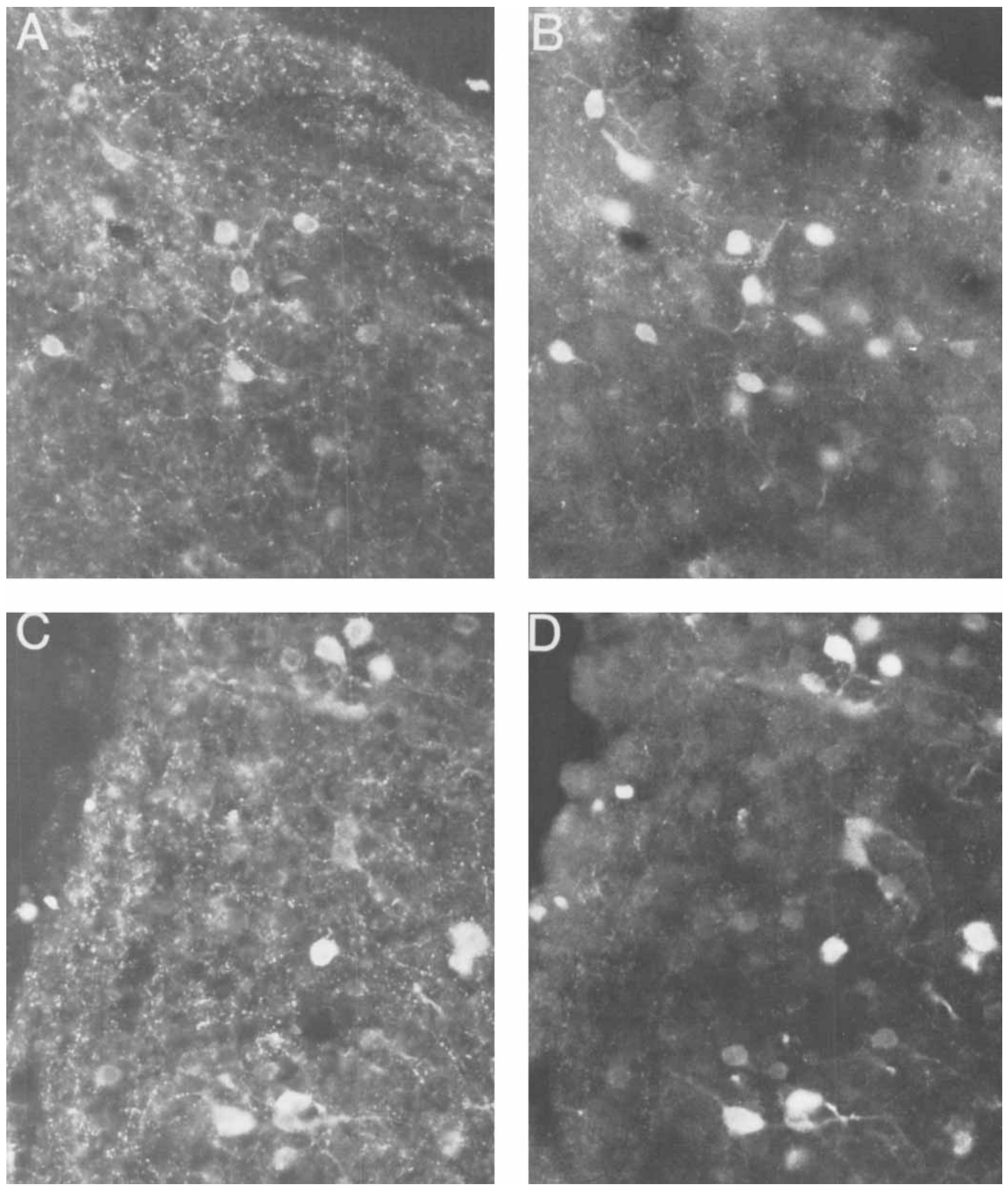

Fig. 15. Pairs of photomicrographs of two transverse sections through the turtle brain that had been processed acccording to the simultaneous immunofluorescence procedure for the dual localization of LENK and BAM22P. A. LENK + FITC-labeled perikarya and fibers in a single field of view through area d of the striatum. B. BAM $22 \mathrm{P}+$ TRITC-labeled perikarya and fibers present in this same field of view. Note that the same

perikarya are labeled in both and that some of the perikarya appear to be more heavily labeled for BAM22P than for LENK. Medial is to the right in A and B. C. LENK + FITC-labeled perikarya and fibers in a single field of view through the preoptic region. D. BAM22P+ TRITC-labeled perikarya and fibers present in this same field of view. Note that the same perikarya are labeled for both LENK and BAM22P. Medial is to the left in C and D. 
MENK to LENK levels was about 25:1, which differs markedly from the typical ratio in mammals. Since Kilpatrick et al. ('83) enzymatically treated their tissue extracts, it is possible that the small amounts of LENK detected in their procedures had been enzymatically cleaved from the $\mathrm{N}$ terminus of the dynorphin peptides present in frog CNS (Cone and Goldstein, '82). Thus, although the LENK sequence may be present in proenkephalin in some amphibians, in the amphibian species that have been studied it seems likely that the LENK sequence is not present in proenkephalin. Whether the absence of LENK from proenkephalin in frogs represents the primitive amphibian condition, one that may have been passed on to reptiles, or whether it is a derived condition that evolved in the frog lineage is uncertain. Studies of members of the other extant orders of amphibians (urodeles and apodans) will be required to resolve this issue.

Even if LENK were absent from proenkephalin in ancestral amphibians, this does not rule out the possibility that the LENK sequence became part of proenkephalin during the early evolution of reptiles. The data presented here, the work of Lindberg and White ('86), and previous studies on the avian nervous system, in fact, strongly favor the conclusion that the LENK sequence is contained within proenkephalin of birds and reptiles. First, in the present study the ImmunoNuclear anti-LENK antiserum was specific for LENK and produced substantial LENK + labeling even when blocked with $100 \mu \mathrm{M}$ Dynorphin $\mathrm{A}(1-8)$ or $200 \mu \mathrm{M}$ MENK. In contrast, labeling with this antiserum in Xenopus was essentially completely blocked by $50 \mu \mathrm{M}$ Dynorphin A(1-8) or MENK (Reiner, unpub. obs.). Further, in an unpublished RIA study of the relative levels of MENK and LENK in different regions of the turtle central nervous system, the ratio of MENK to LENK ranged from about 4:1 to $2: 1$, comparable to that found in mammals (J.D. White, A. Reiner and J.F. McKelvy, cited in Reiner, '87). Similarly, Lindberg and White ('86) report a MENK:MERF:LENK ratio for whole turtle brain of approximately $4: 1: 1$. Further, in pigeon brain the MENK to LENK ratio has been found to range from $10: 1$ to $3: 1$ on a regional basis (Bayon et al., '80). In chicken spinal cord a 2.5:1 ratio has been reported (Maderdrut et al., '86). It seems unlikely that the substantial levels of LENK immunoreactivity detected in these studies could represent LENK enzymatically cleaved from dynorphin peptides or cross-reactive recognition of dynorphin peptides. Dynorphin peptide levels found in the mammalian nervous system are only about $1 / 10$ of those found for enkephalin peptides (Zamir et al., '84). Finally, White et al. ('85) have recently reported, based on HPLC studies, that LENK and MENK are both present in avian neural tissue. Thus, the currently available data favor the view that LENK is part of proenkephalin in birds and reptiles, as well as in mammals.

It seems very likely that MERF and MENK are also part of this precursor in reptiles, based on the present data, on the work of Lindberg and White ('86), and on the HPLC data demonstrating that MERF and MENK appear to be present in the avian nervous system (Kilpatrick et al., '83, White et al., '85; Maderdrut et al., '86). In light of the radioimmunoassay data cited above, therefore, it appears likely that turtle proenkephalin contains four copies of the MENK sequence, one copy of the LENK sequence, and one of the MERF sequence. The work of Lindberg and White ('86) indicates that the MENK:LENK:MERF ratio may not be 4:1:1 in proenkephalin of lizards and crocodilians, or if it is, proenkephalin is apparently processed differently in lizards and crocodilians than in turtles. Finally, the present data also indicate that a high molecular weight peptide(s) similar to BAM22P and/or PEPE is present in turtle proenkephalin. This substance presumably occupies the same location in turtle proenkephalin as do Peptide $\mathrm{E}$ and BAM22P in mammalian proenkephalin. The results suggest that such a high molecular weight enkephalin peptide(s) may be a major product of proenkephalin in at least some portions of the turtle central nervous system. The results of Lindberg and White ('86) indicate, however, that in turtle brain on the whole, proenkephalin is largely processed to the low molecular weight enkephalin peptides. Finally, the MERGL sequence, as such, appears to be absent from turtle proenkephalin. It is possible, however, that turtle proenkephalin contains a sequence resembling MERGL, as appears true in frogs, that does not cross-react with the anti-MERGL antiserum used in this study or that of Lindberg and White ('86). The MERGL sequence is also reportedly absent from proenkephalin in frogs (as noted above), lizards, crocodilians, and birds (Kilpatrick et al., '83; Martens and Herbert, '84; Lindberg and White, '86). Thus, MERGL as such may be a uniquely mammalian enkephalin peptide. Only placental mammals have been studied, however, and it is possible that MERGL may not have evolved until a relatively late point in mammalian evolution.

\section{Comparison to previous studies in reptiles}

Several previous studies have reported the distribution of enkephalin labeling in the CNS in reptiles. Two of these studies used Chang's anti-LENK antiserum (Naik et al., '81; Brauth, '84), and a third used anti-MENK and antiLENK from a different source (Wolters et al., '86). In light of the potential cross-reactivity of antisera against the enkephalin pentapeptides with dynorphin peptides, it is possible that some of the enkephalin-positive labeling described in the previous studies represented cross-reactive labeling of dynorphin peptides. As discussed, the use of multiple specific antienkephalin antisera in the present study ensures that the pattern described here represents the pattern of enkephalin distribution. Despite the possibility of crossreactive dynorphin labeling in previous studies on reptiles, the labeling patterns described here are largely similar to those in previous studies. This is not surprising since enkephalin and dynorphin are very similarly distributed in the nervous system, as reported in mammals (Khachaturian et al., '85) and as seen in birds and reptiles (Reiner et al., '84a,b; Reiner, '86a). Major similarities were observed between the present study and previous studies on the distribution of enkephalin in reptiles. At the telencephalic level, all reptiles possess much higher levels of enkephalinergic fibers and cell bodies in the basal ganglia than in the DVR and cortex, with essentially all basal ganglia enkephalinergic neurons being localized in the striatum (area $\mathrm{d}$ and PA in turtles) and fiber densities being higher in the GP. In addition, enkephalinergic neurons are present in such "striatal" regions as the TuOl, and enkephalinergic fibers are prominent in such "pallidal" regions as the ventral paleostriatum. Within the DVR, enkephalin ergic neurons are sparse in all reptiles studied, whereas within cortex, enkephalinergic neurons and fibers are most abundant in the medial portions of cortex. The septal region of all reptiles also shows an abundance of enkephalinergic fibers and neurons. Within the diencephalon, enkephalinergic fibers and neurons are abundant in the hypothalamus, but much sparser in more dorsal parts of the diencephalon. Within the thalamus, enkephalinergic fibers are 
present in cell groups with nonspecific telencephalic projections, but are entirely absent or extremely sparse in sensory thalamic projection nuclei. In the midbrain, enkephalinergic neurons are prominent in nDCP in all reptiles, and this cell group gives rise to an enkephalinergic input to the tectum that presumably terminates in the deeper tectal layers (Brauth and Kitt, '80; Reiner et al., '80; Brauth and Reiner, '82; ten Donkelaar and de Boer-van Huizan, '81). Additional enkephalinergic neurons that innervate retinorecipient tectal layers are present in deep or inter mediate tectum in all reptiles. Tegmental levels of enkephalin are low, but some enkephalinergic fibers and neurons are present in the medial tegmentum. Although dynorphinergic fibers and terminals that arise from striatal neurons are prominent in the substantia nigra, enkephalinergic fibers were largely absent from the substantia nigra (Reiner, '83, '86a). Within the isthmic region, many enkephalinergic neurons have been reported in $\mathrm{Pb}$ and the nucleus of LL in turtles and lizards. Enkephalinergic fibers are prominent in $\mathrm{Pb}, \mathrm{LoC}$, and the central gray. Within the rhombencephalon, noteworthy accumulations of enkephalinergic neurons are present in the raphe, near nVII and within and lateral to caudal TTd. The enkephalinergic cells observed near $\mathrm{nVII}$ in turtles are present in the same region as centrifugal neurons projecting to the cochlea (Strutz, '82), which in mammals have been shown to be enkephalinergic (Altschuler et al., '84). In the spinal cord, enkephalinergic neurons and fibers are most prominent in the dorsal root entry zone and the dorsal horn.

Some differences in enkephalin distribution are present in the published studies. Enkephalinergic neurons were not observed in the supraoptic nucleus in the present study, but they were by Naik et al. ('81) in lizards. In rats, dynorphinergic neurons, but not enkephalinergic neurons, have been observed in the supraoptic nucleus (nSO) (Watson et al., '82a). In other mammals, however, enkephalinergic as well as dynorphinergic neurons appear to be present in $\mathrm{nSO}$ (Vanderhaeghen et al., '83; Khachaturian et al., '85). Thus, it is uncertain if the reported difference between turtles and lizards regarding enkephalinergic neurons in nSO is a real species difference or whether the reported enkephalin staining in nSO neurons in lizards stems from cross-reactive labeling of dynorphinergic neurons (Chang's antiLENK antiserum was used in the lizard study). Other minor differences were also observed. Naik et al. ('81) did not observe enkephalinergic neurons in $\mathrm{Ra}$, medial tegmentum, and La. These authors did not pretreat their lizards with colchicine, however, and it is possible that such treatment would have made enkephalinergic neurons evident in these cell groups.

\section{Comparison to previous studies in birds and mammals}

The enkephalin labeling patterns in the present study bear a great resemblance to those in mammals and birds (Cuello and Paxinos, '78; Sar et al., '78; Wamsley et al., '80; Bayon et al., '80; Del Fiacco et al., '80, '82; De Lanerolle et al., '81; Reiner et al., ' $82 \mathrm{~b}$, ' $84 \mathrm{a}, \mathrm{b}$; Khachaturian et al., '83a,c, '85). The resemblance to birds is greater than to mammals, presumably owing to the greater overall similarity between the brains of reptiles and the brains of birds than between the brains of reptiles and mammals. A few of the major characteristics of the enkephalinergic labeling pattern common to mammals, birds, and reptiles are: 1) high levels of enkephalin in a population of striatal neurons and of pallidal fibers (indicating the presence of a population of enkephalinergic striatopallidal projection neurons), 2) low numbers of enkephalin neurons and fibers in telencephalic cortex or its reptilian and avian equivalents (i.e., cortex and DVR in reptiles, Wulst and DVR in birds), 3) high levels of hypothalamic enkephalin, notably in preoptic neurons and nVH fibers, 4) high levels of enkephalinergic fibers in the central and periventricular gray of the midbrain, and 5) high levels of enkephalinergic fibers associated with TTd of the medulla and the dorsal horn of the spinal cord. It seems very likely that these enkephalinergic systems have been inherited by reptiles, birds, and mammals from their common reptilian ancestors. The particular significance of the similarities observed at telencephalic levels has been considered, together with other shared features of telencephalic organization, in previous discussions of the evolution of the basal ganglia (Reiner et al., '84a).

Major features of the enkephalinergic labeling pattern that reptiles share in common with birds but not with mammals include the high levels of enkephalin in the pretectal cell group, $\mathrm{nDCP}$ (which is homologous to the avian lateral spiriform nucleus, or SpL), and its projection to the tectum (Reiner et al., '80, '82a,b), the high levels of enkephalin in neurons with radially ascending dendrites that enter the retinorecipient tectum neuropil, and the high levels of enkephalin in neurons of nucleus laminaris of the midbrain (which appears to be comparable to the avian nucleus intercollicularis). The apparent absence in mammals of an enkephalinergic correspondent of the reptilian nDCP-tectal pathway is of particular interest. In both reptiles and birds, this enkephalinergic cell group is the major target of the pallidal portion of the basal ganglia (Brauth and Kitt, '80; Reiner et al., '80, '82a,b). The neurons of $\mathrm{nDCP}$ and SpL also contain GABA and the neurotensin-related hexapeptide LANT6 (Reiner, '86b; Reiner and Carraway, '87) and may influence neurons of the deep tectal layers that project to hindbrain premotor cell groups. This basal ganglia-tectal pathway may be the major circuit by which the reptilian and avian basal ganglia influence motor functions. Despite the prominence of this pretectal cell group in reptiles and birds, a comparable enkephalinergic cell group has not been observed in the pretectum of mammals, although the nucleus of the posterior commissure shows some connectional similarity to nDCP and SpL (Reiner et al., '84a). Overall, the differences noted between birds and reptiles on one hand and mammals on the other appear to relate mainly to the larger size and somewhat different cytoarchitectural organization of the midbrain roof in birds and reptiles compared to that in mammals (Reiner and Karten, '82), and to an attendant hypertrophy of cell groups related to the midbrain roof in birds and reptiles compared to mammals.

\section{Conclusions}

In general, the present results in conjunction with previous studies on the molecular structure and distribution of other neuropeptides (e.g., substance P, CCK8, somatostatin, and neurotensin) in the turtle central nervous system (King and Millar, '79; Carraway et al., '82; Reiner et al., '84c; Weindl et al., '84; Reiner and Beinfeld, '85) suggest that neuropeptide evolution among amniotes has been very conservative. The present results show that a proenkephalinlike peptide that contains LENK, MENK, MERF, PEPE/ BAM22P, or highly similar peptides appears to be present in neurons of the turtle central nervous system. These 
neurons and their fibers are widespread and abundant in the turtle central nervous system and their distribution shows many similarities with that in birds and mammals. The present results thus suggest that many of the major features of enkephalin distribution in birds and mammals had already arisen in the reptilian ancestors of living birds, reptiles, and mammals. Since opiate receptors of the mu and delta types have been reported in reptiles (Pert et al., '74; Buatti and Pasternak, '81; Moon-Edley et al., '82), it seems likely that the enkephalin peptides exert their physiological effects in turtles by means of the same receptor types as in birds and mammals. Thus, the enkephalins appear to play a functional role in many of the same systems in reptiles as in birds and mammals, and it seems likely that this role is mediated by similar synaptic events.

\section{ACKNOWLEDGMENTS}

Special thanks are in order to Pat Lindaman, Alann Solina, Gary Henderson, Lynn Cutler, and Debora Romeo for technical, illustrative, secretarial, and photographic assistance. This research was supported by NS-19620.

\section{LITERATURE CITED}

Akil, H., S.J. Watson, E. Young, M.E. Lewis, H. Khachaturian, and J.M. Walker (1984) Endogenous opioids: Biology and function. Ann Rev. Neurosci. 7:223-255.

Altschuler, R.A, J. Fex, M.H. Parakkal, and F. Eckenstein (1984) Co-localization of enkephalin-like and choline acetyltransferase-like immunoreactivities in olivocochlear neurons of the guinea pig. J. Histochem. Cytochem. 32:839-843.

Ariens Kappers, C.U., G.C. Huber, and E.C. Crosby (1936) The Comparative Anatomy of the Nervous System of Vertebrates, Including Man. New York: MacMillan.

Balaban, C.D., and P.S. Ulinski (1981a) Organization of thalamic afferents to anterior dorsal ventricular ridge in turtles. I. Projections of thalamic nuclei. J. Comp. Neurol. 200:95-129.

Balaban, C.D., and P.S. Ulinski (1981b) Organization of thalamic afferents to anterior dorsal ventricular ridge in turtles. II. Properties of the rotundo-dorsal nucleus map. J. Comp. Newrol. 200:131-150.

Bass, A.H., and R.G. Northcutt (1981) Retinal recipient nuclei in the painted turtle, Chrysemys picta: An autoradiographic and HRP study. J. Comp. Neurol. 199:97-112.

Bayon, A., L. Koda, E. Battenberg, R. Aarens, and F.E. Bloom (1980) Re gional distribution of endorphin, met $t^{5}$-enkephalin and leu ${ }^{5}$-enkephalin in the pigeon brain. Neurosci. Lett. 16:75-80.

Blahser, S., and M.P. Dubois (1980) Immunocytochemical demonstration of met-enkephalin in the central nervous system of the domestic fowl. Cell Tiss. Res. 213:53-68.

Bloch, B., A. Baird, N. Ling, R. Benoit, and R. Guillemin (1983) Immunohis tochemical evidence that brain enkephalins arise from a precursor similar to adrenal preproenkephalin. Brain Res. 263:251-257.

Bloom, F.E., E. Battenberg, J. Rossier, N. Ling, and R. Guillemin (1978) Neurons containing Bendorphin in rat brain exist separately from those containing enkephalin: Immunocytochemical studies. Proc. Natl. Acad. Sci. 75:1591-1595.

Brauth, S.E. (1984) Enkephalin-like immunoreactivity within the telen cephalon of the reptile Caiman crocodilus. Neuroscience 11(2):345-358.

Brauth, S.E., and C.A. Kitt (1980) The paleostriatal system of Caiman crocodilus. J. Comp. Neurol. 189:437-465.

Brauth, S.E., and A. Reiner (1982) A pretectal-tectal enkephalin connection: Immunohistochemical studies of homologous systems in reptiles. Soc. Neurosci. Abs. 8:116.

Brauth, S.E., A. Reiner, C.A. Kitt, and H.J. Karten (1983) The substance Pcontaining striato-tegmental path in reptiles: An immunohistochemical study. J. Comp. Neurol. 219:305-327.

Buatti, M.C., and G.W. Pasternak (1981) Multiple opiate receptors: Phylogenetic differences. Brain Res. 218:400-405.

Carraway, R.E., S.E. Ruane, and H.R. Kim (1982) Distribution and immunochemical character of neurotensin-like material in representative vetebrates and invertebrates: Apparent conservation of the $\mathrm{COOH}$-terminal region during evolution. Peptides 1:115-123.
Comb, M., P.H. Seeburg, J. Adelman, L. Eiden, and E. Herbert (1982) Primary structure of the human Met- and Leu-enkephalin precursor: and its mRNA. Nature (Lond.) 295:663-666.

Cone, R.I., and A. Goldstein (1982) A dynorphin-like opioid in the central nervous system of an amphibian. Proc. Natl. Acad. Sci. 79:3345-3349.

Coons, A.H. (1958) Fluorescent antibody methods. In J.F. Danielli (ed) General Cytochemical Methods. New York: Academic Press, pp. 399 422.

Cuello, A.C., and G. Paxinos (1978) Evidence for a long Leu-enkephalin striopallidal pathway in rat brain. Nature (Lond.) 271:178-180.

Cuello, A.C., C. Milstein, R. Coutre, B. Wright, J.V. Priestley, and J. Jarvis (1984) Characterization and immunocytochemical application of monoclonal antibodies against enkephalins. J. Histochem. Cytochem., 32:947957.

Del Fiacco, M., and A.C. Cuello (1980) Substance P and enkephalin-containing neurones in the rat trigeminal system. Neuroscience 5:803-815.

Del Fiacco, M., G. Paxinos, and A.C. Cuello (1982) Neostriatal enkephalinimmunoreactive neurons project to the globus pallidus. Brain Res. 231:1 179.

De Lanerolle, N.C., R.P. Elde, S.B. Sparber, and M. Fricke (1981) Distribution of methionine-enkephalin immunoreactivity in the chick brain: An immunohistochemical study. J. Comp. Neurol. 199:513-533.

Dockray, G.J., C. Vaillant, and R.G. Williams (1981) New vertebrate braingut peptide related to a molluscan neuropeptide and an opioid peptide. Nature 293:656-657.

Doerr-Schott, J., M.P. Dubois, and C. Lichte (1981) Immunohistochemical localization of substances reactive to antisera against alpha- and beta endorphin and met-enkephalin in the brain of Rana temporaria $L$. Cell Tiss. Res. 217:79-92

Dores, R.M. (1982a) Localization of multiple forms of ACTH- and betaendorphin-related substances in the pituitary of the reptile, Anolis carolinensis. Peptides 3:913-924.

Dores, R.M. (1982b) Evidence for a common precursor for alpha-MSH and beta-endorphin in the intermediate lobe of the pituitary of the reptile Anolis carolinensis. Peptides 3:925-935

Dores, R.M. (1983) Further characterization of the major forms of reptile beta-endorphin. Peptides 4:897-905.

Dores, R.M., and A. Surprenant (1983) Biosynthesis of multiple forms of beta-endorphin in the reptile intermediate pituitary. Peptides 4:889896

Dores, R.M., and A. Surprenant (1984) In vitro synthesis of ACTH-and betaendorphin-related substances in the pars distalis of Anolis carolinensis. Gen. Comp. Neurol. 56:90-99.

Dores, R.M., H. Khachaturian, S.J. Watson, and H. Akil (1984) Localization of neurons containing pro-opiomelanocortin-related peptides in the hypothalamus and midbrain of the lizard, Anolis carolinensis: Evidence for region specific processing of beta-endorphin. Brain Res. 324:384389.

Dubois, M.P., R. Billard, B. Breton, and R.E. Peter (1979) Comparative distribution of somatostatin, LHRH, neurophysin and alpha-endorphin in the rainbow trout: An immunocytochemical study. Gen. Comp. En docrinol. 37:220-232

Edley, S.M., L. Hall, M. Herkenham, and C.B. Pert (1982) Evolution of striatal opiate receptors. Brain Res. 249:184-188.

Erichsen, J.T., A. Reiner, and H.J. Karten (1982) Co-occurrence of substance P-like and leu-enkephalin-like immunoreactivities in neurons and fibers of the avian nervous system. Nature (Lond.) 295:407-410.

Finger, T.E. (1981) Enkephalin-like immunoreactivity in the gustatory lobes and visceral nuclei in the brains of goldfish and catfish. Neurosci. $6: 2747-2758$

Finley, J.C.W., J.L. Maderdrut, and P. Petrusz (1981) The immunocytochemical localization of enkephalin in the central nervous system of the rat. J. Comp. Neurol. 198:541-565.

Gall, C., N. Brecha, H.J. Karten, and K.J. Chang (1981) Localization of enkephalin-like immunoreactivity to identified axonal and neuronal populations of the rat hippocampus. J. Comp. Neurol 198:335-350.

Georges, D., and M.P. Dubois (1984) Methionine-enkephalin-like immunoreactivity in the nervous ganglion and ovary of a protochordate, Ciona intestinalis. Cell Tiss. Res. 236:165-170.

Giraud, A.S., R.G. Williams, and G.J. Dockray (1984) Evidence for different patterns of post-translational processing of pro-enkephalin in the bovine adrenal colon and striatum indicated by radioimmunoassay using re gion-specific antisera to met-enk-arg ${ }^{6}-\mathrm{phe}^{7}$ and met-enk-arg ${ }^{6}-\mathrm{gly}^{7} \mathrm{eu}^{8}$. Neurosci. Lett. 46:223-228.

Gold, M.R., and T.E. Finger (1982) Localization of enkephalin immunoreac tivity in the brain of the lamprey. Soc. Neurosci. Abs. 7:85. 
Goldstein, A., S. Tachibana, L.I. Lowney, M. Hunkapiller, and L. Hood (1979) Dynorphin-(1-13), an extraordinarily potent opioid peptide. Proc. Natl. Acad. Sci. 76:6666-6670.

Gubler, V., P. Seeburg, B.J. Hoffman, L.P. Gage, and S. Udenfriend (1982) Molecular cloning establishes proenkephalin as precursor of enkephalin-containing peptides. Nature (Lond.) 295:206-208.

Hall, W.C., and F.F. Ebner (1970) Thalamotelencephalic projections in the turtle (Pseudemys scripta). J. Comp. Neurol. 140:101-122.

Hall, J.A., R.E. Foster, F.F. Ebner, and W.C. Hall (1977) Visual cortex in a reptile, the turtle (Pseudemys scripta and Chrysemys picta). Brain Res. 130:197-216

Herbert, E., O. Civelli, J. Douglas, G. Martens, and H. Rosen (1985) Generation of diversity of opioid peptides. In Biochemical Actions of Hor mones, Vol. 12. New York: Academic Press, pp. 1-36.

Hokfelt, T., A. Ljungdahl, L. Terenius, R. Elde, and G. Nilsson (1977) Immunohistochemical analysis of peptide pathways possibly related to pain and analgesis: Enkephalin and substance. P. Proc. Natl. Acad. Sci 74:3081-3085.

Hughes, J., T.W. Smith, J.W. Kosterlitz, L.A. Fothergill, V.A. Morgan, and H.R. Morris (1975) Identification of two related pentapeptides from th brain with potent opiate agonist activity. Nature (Lond.) 258:577-579.

Jackson, I.M.D., J.L. Bolaffi, and R. Guillemin (1980) Presence of immunoreactive $\beta$-endorphin and enkephalin-like material in the retina and other tissues of the frog, Rana pipiens. Gen. Comp. Endocrinol., 42:505508.

Jones, B.N., S.K. Shively, D.L. Kilpatrick, K. Kojima, and S. Udenfriend (1982a) Enkephalin biosynthetic pathway: A 5300 dalton adrenal poly peptide that terminates at its $\mathrm{COOH}$ end with the sequence (Met) enkephalin-Arg-Gly-Leu-COOH. Proc. Natl. Acad. Sci, 77:5512-5514.

Jones, B.N., J.K. Shively, D.L. Kilpatrick, A.S. Stern, R.V. Lewis, K. Kojima, and S. Udenfriend (1982b) Adrenal opioid proteins of 8,600 and 12,600 daltons: Intermediates in proenkephalin processing. Proc. Natl. Acad. Sci. 79:2096-2100.

Kakidani, H., Y. Furutani, H. Takahashi, M. Noda, Y. Morimoto, T. Hirose M. Asai, S. Inayama, S. Nakanishi, and S. Numa (1982) Cloning and sequence analysis of cDNA for porcine B-neo-endorphin/dynorphin precursor. Nature (Lond.) 298:245-249.

Khachaturian, H., M.E. Lewis, and S.J. Watson (1983a) Enkephalin systems in diencephalon and brain stem of the rat. J. Comp. Neurol. 220:310320.

Khachaturian, H., M.E. Lewis, and S.J. Watson (1983b) Co-localization of proenkephalin peptides in rat brain regions. Brain Res. 279:369-373.

Khachaturian, H., M.E. Lewis, V. Hollt, and S.J. Watson (1983c) Telencephalic enkephalinergic systems in the rat brain. J. Neurosci. 3:844-855.

Khachaturian, H., M.E. Lewis, M.K.-H. Schafer, and S.J. Watson (1985) Anatomy of the CNS opioid systems. Trends in Neurosciences 8:111119.

Khachaturian, H., R.M. Dores, S.J. Watson, and H. Akil (1984) Beta-endorphin/ACTH immunocytochemistry in the CNS of the lizard, Anolis carolinensis: Evidence for a major mesencephalic cell group. J. Comp. Neurol. 229:576-584.

Kilpatrick, D.L., R.D. Howells, H.-W. Lahn, and S. Udenfriend (1983) Evidence for a proenkephalin-like precursor in amphibian brain. Proc. Natl. Acad. Sci. 80:5772-5775.

Kilpatrick, D.L., B.N. Jones, K. Kojima, and S. Udenfriend (1981) Identification of the octapeptide (Met) enkephalin-Arg ${ }^{6}-$ Gly $^{7}$-Leu ${ }^{8}$ in extracts of bovine adrenal medulla. Biochem. Biophys. Res, Commun. 13:698-705.

King, J.A., and R.P. Millar (1979) Phylogenetic and anatomical distribution of somatostatin in vertebrates. Endocrinol. 105:1322-1329.

King, J.A., and R.P. Millar (1980) Radio immunoassay of methionine ${ }^{5}$. enkephalin sulphoxide: Phylogenetic and anatomical distribution. Peptides. $1: 211-216$

Kuljis, R, and H.J. Karten (1982) Laminar organization of peptide-like immunoreactivity in the anuran optic tectum. I. Comp. Neurol. 212;188201.

Kunzle, H., and W. Woodson (1982) Mesodiencephalic and other target regions of ascending spinal projections in the turtle, Pseudemys scripta elegans. J. Comp. Neurol. 212:188-210.

LaValley, A.L., and R.H. Ho (1983) Substance P, somatostatin and methionine-enkephalin immunoreactive elements in the spinal cord of the domestic fowl, Gallus domesticus. J. Comp. Neurol. 213:406-413.

Lewis, R.V., A.S. Stern, J. Rossier, S. Stein, and S. Udenfriend (1979) Putative enkephalin precursors in bovine adrenal medulla. Biochem. Biophys. Res. Commun. 89:822-829.

Lindberg, I., and L. White (1986) Reptilian enkephalins: Implications for the evolution of proenkephalin. Archives of Biochemistry and Biophysics 245:1-7.
Loh, Y.P. (1979) Immunological evidence for two common precursors to corticotropins, endorphins and melanotropins in the neurointermediate lobe of the toad pituitary. Proc. Natl. Acad. Sci. 76:796-800.

McGinty, J.F., S.J. Henriksen, A. Goldstein, L. Terenius, and F.E. Bloom (1983) Dynorphin is contained within hippocampal mossy fibers: Immunohistochmeical alterations after kainic acid administration and colchicine-induced neurotoxicity. Proc. Natl. Acad. Sci. 80:589-593.

Maderdrut, J.L., I. Merchenthaler, D.K. Sundberg, N. Okado, and R.W. Oppenheim (1986) Distribution and development of proenkephalin-like immunoreactivity in the Iumbar spinal cord of the chicken. Brain Res. (in press).

Majane, E.A., M.J. Iadarola, and H.Y.T. Yang (1983) Distribution of Met ${ }^{5}$. enkepahlin-Arg ${ }^{6}$, Phe $^{7}$ in rat spinal cord. Brain Res. 264:336-339.

Martens, G., and E. Herbert (1984) Polymorphism and absence of Leuenkephalin sequences in proenkephalin genes in Xenopus laevis. Nature (Lond.) 310:251-254.

Miller, R.J., K.J. Chang, B. Cooper, and P. Cuatrecasas (1978) Radioimmunoassay and characterization of enkephalins in rat tissues. J. Biol. Chem. 253:531--538.

Mizuno, K., N. Minamino, K. Kangawa, and H. Matsuo (1980) A new family of endogenous big Met-enkephalins from bovine adrenal medulla: Purification and structure of docacosa (BAM22P) and dicosapeptide (BAM20P) with very potent opiate activity. Biochem. Biophys. Res. Commun. 97:1283-1290.

Naik, C.R., M. Sar, and W.E. Stumpf (1981) Immunohistochemical localization of enkephalin in the central nervous system and pituitary of the lizard, Anolis carolinensis. J. Comp. Neurol. 198:538-601.

Noda, M., Y. Furutani, H. Takahashi, M. Toyosato, T. Hirose, S. Inayama, S. Nakanishi, and S. Numa (1982) Cloning and sequence analysis of cDNA for bovine adrenal preproenkephalin. Nature (Lond.) 295:202206.

Northcutt, R.G. (1981) Evolution of the telencephalon in non-mammals. Ann. Rev. Neurosci. 4:301-350.

Northeutt, R.G., A. Reiner, and H.J. Karten (1983) The basal ganglia of spiny dogfish: An immunohistochemical study. Anat. Rec. 208:128A.

Northcutt, R.G., A. Reiner, and H.J. Karten (1986) An immunohistochemical study of the telencephalon of the spiny dogfish, Squalus acanthias. J. Comp. Neurol. (in press).

Nozaki, M., and A. Gorbman (1984) Distribution of immunoreactive sites for several components of pro-opiocortin in the pituitary and brain of adult lampreys, Petromyzon marinus and Entosphenus tridentatus. Gen. Comp. Endocrinol. 53:335-352.

Nozaki, M., and A. Gorbman (1985) Immunoreactivity for met-enkephalin and substance $P$ in cells of the adenohypophysis of larval and adult sea lampreys, Petromyzon marinus. Gen. Comp. Endocrinol. 57:172-183.

Pert, C.B., D. Aposhian, and S.H. Snyder (1974) Phylogenetic distribution of opiate receptor binding. Brain Res. 75:356-361.

Pickel, V.M., K.V. SumaI, S.C. Bechley, R.J. Miller, and D.J. Reis (1980) Immunocytochemical localization of enkephalin in the neostriatum of rat brain: A light- and electron-microscopical study. J. Comp. Neurol. 189:721-740.

Powers, A.S., and A. Reiner (1980) A stereotaxic atlas of the forebrain and midbrain of the eastern painted turtle (Chrysemys picta picta). J. Hirnforsch. 21:125-159.

Reaves, T.A., Jr., and J.N. Hayward (1980) Functional and morphological studies of peptide-containing neuroendocrine cells in goldfish hypothalamus. J. Comp. Neurol. 193:777-788.

Reiner, A. (1983) Comparative studies of opioid peptides: Enkephalin distribution in turtle central nervous system. Soc. Neurosci. Abs. 9:439.

Reiner, A. (1986a) The co-occurrence of substance P-like immunoreactivity and dynorphin-like immunoreactivity in striatonigral and striatopallidal projection neurons in pigeons and turtles. Brain Res. 371:155-161.

Reiner, A. (1986b) The extensive co-occurrence of GABA and the neurotensin-related hexapeptide LANT6 in the avian brain. Anat. Ree. 214:106A.

Reiner, A. (1987) Neuropeptides in the reptilian nervous system. In C. Gans and R.G. Northcutt (eds): Biology of the Reptilia. Academic Press (in press).

Reiner, A., and M.C. Beinfeld (1985) The distribution of cholecystokinin-8 in the central nervous system of turtles: An immunohistochemical and biochemical study. Brain Res. Bull. 15:167-181.

Reiner, A., and R.E. Carraway (1987) Immunohistochemical and biochemical studies on Lys $^{8}-\mathrm{Asn}^{9}$-Neurotensin ${ }^{8-13}$ (LANT6)-related peptides in the basal ganglia of pigeons, turtles, and hamsters. J. Comp. Neurol. (in press).

Reiner, A., and H.J. Karten (1982) Laminar distribution of the cells of origin of the descending tectofugal pathways in the pigeon (Columba livia). J. Comp. Neurol, 204:165-187. 
Reiner, A., and H.J. Karten (1985) Comparison of olfactory bulb projections in pigeons and turtles. Brain Behav. Evol. 27:11-27.

Reiner, A., and R.G. Northcutt (1987) An immunohistochemical study of the telencephalon of the African lungfish, Protopterus annectens. J. Comp. Neurol, 256: 463-481.

Reiner, A., and A.S. Powers (1978) Intensity and pattern discrimination in turtles following lesions of nucleus rotundus. J. Comp. Physiol. Psych. 92: $1156-1168$

Reiner, A., and A.S. Powers (1980) The effects of extensive forebrain lesions on visual discriminative performance in turtles (Chrysemys picta picta) Brain Res. 192:327-338.

Reiner, A., and A.S. Powers (1983) The effects of lesions of telencephalic visual structures on visual discriminative performance in turtles (Chry. semys picta picta). J. Comp. Neurol. 218:1-24.

Reiner, A., S.E. Brauth, and H.J. Karten (1984a) Evolution of the amniote basal ganglia. Trends in Neurosciences 7:320-325.

Reiner, A., N.C. Brecha, and H.J. Karten (1982a) Basal ganglia pathways to the tectum: The afferent and efferent connections of the lateral spiriform nucleus of pigeons. J. Comp. Neurol. 208:16-36.

Reiner, A., H.J. Karten, and N.C. Brecha (1982b) Enkephalin-mediated basal ganglia influences over the optic tectum: Immunohistochemistry of the tectum and the lateral spiriform nucleus in pigeon. J. Comp Neurol. 208:37-53.

Reiner, A., H.J. Karten, and A.R. Solina (1983) Substance P: Localization within paleostriatal-tegmental pathways in the pigeon. Neuroscience 9:61-85.

Reiner, A., S.E. Brauth, C.A. Kitt, and H.J. Karten (1980) Basal ganglionic pathways to the tectum: Studies in reptiles. J. Comp. Neurol. 193:565589.

Reiner, A., B.M. Davis, N.C. Brecha, and H.J. Karten (1984b) The distribution of enkephalinlike immunoreactivity in the telencephalon of the adult and developing domestic chicken. J. Comp. Neurol. 228:245-262.

Reiner, A., W.D. Eldred, M.C. Beinfeld, and J.E. Krause (1985) The cooccurrence of a substance P-like peptide and cholecystokinin- 8 in a fiber system of turtle cortex. J. Neurosci. 5:1527-1544.

Reiner, A., J.E. Krause, K.T. Keyser, W.D. Eldred, and J.F. McKelvy (1984b) The distribution of substance $P$ in turtle nervous system: A radioimmunoassay and immunohistochemical study. J. Comp. Neurol. 226:50 75 .

Riss, W., M. Halpern and F. Scalia (1969) The quest for clues to forebrain evolution-the study of reptiles. Brain Behav. Evol, 2:1-50.

Rossier, J., Y. Audigier, N. Ling, J. Cros, and S. Udenfriend (1980) Metenkephalin-Arg ${ }^{6}-\mathrm{Phe}^{7}$, present in high amounts in brain of rat, cattle and man, is an opioid agonist. Nature (Lond.) 288:88-90.

Ryan, S.M., A.P. Arnold, and R.P. Elde (1981) Enkephalin-like immunoreactivity in vocal control regions of the zebra finch brain. Brain Res. 229:236-240

Rzasa, P., K.V. Kavoustian, and E.K. Prokop (1984) Immunochemical evidence for met-enkephalin-like and leu-enkephalin-like peptides in tis sues of the earthworm, Lubricus terrestris. Comp. Biochem. Physiol. $77 C: 345-350$

Sar, M., W.E. Stumpf, R.J. Miller, K.-J. Chang, and P. Cautrecasas (1978) Immunochemical localization of enkephalin in rat brain and spinal cord. J. Comp. Neurol. 182:17-38.

Schulman, J.A., T.E. Finger, N.C. Brecha, and H.J. Karten (1981) Enkeph alin immunoreactivity in Golgi cells and mossy fibres of mammalian, avian, amphibian and teleost cerebellum. Neuroscience 6:2407-2416.

Simantov, R., R. Goodman, D. Aposhian, and S.H. Snyder (1976) Phylogenetic distribution of a morphine-like peptide "enkephalin." Brain Res. 111:204-211.

Simantov, R., M.J. Kuhar, G.R. Uhl, and S.H. Snyder (1977) Opioid peptide enkephalin: Immunohistochemical mapping in rat central nervous system. Proc. Natl. Acad. Sci. 74:2167-2171.

Stern, A.S., R.V. Lewis, L.S. Kimura, J. Rossier, L.D. Gerber, L. Brink, S. Stein, and S. Udenfriend (1979) Isolation of the opioid heptapeptide Metenkephalin $\left(\mathrm{Arg}^{6}, \mathrm{Phe}^{7}\right.$ ) from bovine adrenal medullary granules and striatum. Proc. Natl. Acad. Sci. 76:6680-6683.

Sternberger, L. (1979) Immunocytochemistry. Second edition. New York: John Wiley and Sons.

Strutz, J. (1982) The origin of efferent fibers to the inner ear in a turtle (Terrapene ornata). Brain Res. 244:165-168. ten Donkelaar, H.J., and R. de Boer-van Huizan (1981) Basal ganglia projections to the brainstem in the lizard Varanus exanthematicus as demonstrated by retrograde transport of horseradish peroxidase. Neurosci. $6: 1567-1590$.

Uhl, G.R., R.R. Goodman, M.J. Kuhar, S.R. Childers, and S.H. Snyder (1979) Immunohistochemical mapping of enkephalin containing cell bodies, fibres and nerve terminals in the brain stem of the rat. Brain Res. 166:75-94.

Uhl, G.R., M.J. Kuhar, and S.H. Snyder (1978) Enkephalin-containing pathway: Amygdaloid efferents in the stria terminalis. Brain Res. 149:223228.

Vanderhaeghen, J.J., F. Lotstra, D.R. Liston, and J. Rossier (1983) Proen kephalin, [Met]enkephalin, and oxytocin immunoreactivities are colocalized in bovine hypothalamic magnocellular neurons. Proc. NatI. Acad. Sci. 80:5139-5143.

Vincent, S.R., T. Hokfelt, I. Christensson, and L. Terenius (1982) Dynorphin immunoreactive neurons in the central nervous system of the rat. Neurosci. Lett. 33:185-190.

Vincent, S.R., T. Hokfelt, I. Christensson, and L. Terenius (1982) Immunohistochemical evidence for a dynorphin immunoreactive striato-nigral pathway. Eur. J. Pharmacol. 85:251-252.

Wamsiey, J.K., W.S. Young, and M.J. Kuhar (1980) Immunohistochemica) localization of enkephalin in rat forebrain. Brain Res. 190:153-174.

Watson, S.J., H. Akil, W. Fishli, A. Goldstein, E. Zimmerman, G. Nilaver, and T.B. van Wimersma Greidanus (1982a) Dynorphin and vasopressin: Common localization in magnocellular neurons. Science 216:95-97.

Watson, S.J., H. Akil, C.W. Richard III, and J.D. Barchas (1978) Evidence for two separate opiate peptide neuronal systems. Nature (Lond.) 275:226-228.

Watson, S.J., H. Khachaturian, H. Akil, D.H. Coy, and A. Goldstein (1982b) Comparison of the distribution of dynorphin and enkephalin systems in brain. Science 218:1134-1136.

Watson, S.J., H. Khachaturian, L. Taylor, W. Fischli, A. Goldstein, and H. Akil (1983) Pro-dynorphin peptides are found in the same neurons throughout rat brain: Immunocytochemical study. Proc. Natl. Acad. Sci. 80:891-894.

Weber, E., C.J. Evans, and J.D. Barchas (1983) Multiple endogeneous ligands for opioid receptors. Trends Neurosci, 6:333-336.

Weber, E., K_A. Roth, and J.D. Barchas (1982) Immunohistochemical distri bution of alpha-neo-endorphin/dynorphin neuronal systems in rat brain: Evidence for co-localization. Proc. Natl. Acad. Sci. 79:3062-3066.

Weiler, R. (1985) Mesencephalic pathway to the retina exhibits enkephalin like immunoreactivity. Neurosci. Lett. 55:11-16.

Weindl, A., J. Triepel, and G. Kuchling (1984) Somatostatin in the brain of the turtle Testudo Hermanni Gmelin. An immunohistochemical mapping study. Peptides 5:91-100.

Wessendorf, M.W., and R.P. Elde (1985) Characterization of an immunofluorescence technique for the demonstration of coexisting neurotransmit ters within nerve fibers and terminals. J. Histochem. Cytochem. 33:984994.

White, J.D., J.E. Krause, H.J. Karten, and J.F. McKelvy (1985) Presence and ontogeny of enkephalin and substance $P$ in the chick ciliary ganglion. J. Neurochem. 45:1319-1322.

Wilczynski, W., and R.G. Northcutt (1983) Connections of the bullfrog striatum: Efferent projections. J. Comp. Neurol. 214:333-343.

Williams, R.G., and G.J. Dockray (1982) Differential distribution of Metenkephalin and Met-enkephalin $\mathrm{Arg}^{6} \mathrm{Phe}^{7}$-like peptides revealed by immunohistochemistry. Brain Res. 240:167-170.

Williams, R.G., and G.J. Dockray (1983) Distribution of enkephalin-related peptides in rat brain: Immunohistochemical studies using antisera to met-enkephalin and met-enkephalin $\mathrm{Arg}^{6} \mathrm{Phe}^{7}$. Neuroscience 9(3):563586.

Wolters, J.G., H.J. ten Donkelaar, and A.A.J. Verhofstad (1986) Distribution of some peptides (substance P, [Leu]enkephalin, [Met]enkephalin) in the brainstem and spinal cord of the lizard Varanus exanthematicus. Neurosci. 18:917-946.

Zamir, N., M. Palkovits, E. Weber, E. Mezey, and M.J. Brownstein (1984) A dynorphinergic pathway of Leu-enkephalin production in rat substantia nigra. Nature (Lond.) 307:643-645.

Zipser, B. (1980) Identification of specific leech neurons immunoreactive to enkephalin. Nature (Lond.) 283:857-858. 